\title{
Investigating Ecosystem Service Trade- offs/synergies and their Influencing Factors: A Case Study in the Yangtze River Delta region of China
}

Cheng Li ( $\nabla$ cheng.li@cumt.edu.cn )

China University of Mining and Technology

Jie Zhao

Jiangsu Normal University

Wenfu Yang

Shanxi Coal Geology Geophysical Surveying Exploration Institute

\section{Research Article}

Keywords: Ecosystem service, trade-off/synergy, TSD indicator, driving factor, spatially heterogeneous, Yangtze River Delta region

Posted Date: February 15th, 2021

DOI: https://doi.org/10.21203/rs.3.rs-197955/v1

License: (c) (1) This work is licensed under a Creative Commons Attribution 4.0 International License. Read Full License 
11 Corresponding author: Cheng Li

12 Xuzhou China 221116

Email: cheng.li@cumt.edu.cn

Telephone: +8618352263764

Fax: $+86516-83591999$

\section{Abstract}

\title{
Investigating ecosystem service trade-offs/synergies and their influencing
} factors: A case study in the Yangtze River Delta region of China

\author{
Cheng $\mathrm{Li}^{\mathrm{a}}$, Jie Zhao ${ }^{\mathrm{b}}$, Wenfu Yang \\ ${ }^{a}$ School of Architecture \& Design, China University of Mining and Technology, Xuzhou 221116, \\ China, Email: cheng.li@cumt.edu.cn \\ ${ }^{b}$ Belt \& Road Institute, Jiangsu Normal University, Xuzhou, 221009, China, Email: \\ jiezhao@jsnu.edu.cn \\ ${ }^{\mathrm{c} S h a n x i ~ C o a l ~ G e o l o g y}$ Geophysical Surveying Exploration Institute, Jinzhong, China, Email: \\ wenfu_yang_99@163.com
}

Address: School of Architecture \& Design, China University of Mining and Technology,

A comprehensive understanding of the trade-off/synergy relationships that exist among multiple ecosystem services (ESs) has become increasingly important for ecological management and sustainable development. However, the determination of the factors that promote trade-off/synergy relationships and the extent to which the driving factors affect these complex relationships have not been well studied, limiting the effectiveness of sustainable ecosystem management. This study employed the Yangtze River Delta region in China as the study area and investigated the spatiotemporal changes in three ESs, namely, carbon storage (CS), water purification (WP), and habitat quality (HQ), 
27 from 2005 to 2015. A trade-off/synergy degree (TSD) indicator was developed that 28 allowed for the quantification of the trade-off/synergy intensity, and the spatial pattern

29 of the TSD between ESs in the YRD region was analyzed. Furthermore, a 30 geographically weighted regression (GWR) model was used to analyze the relationship 31 between the driving factors and trade-offs/synergies. The results revealed that CS, WP, 32 and HQ decreased by $1.17 \%, 2.49 \%$, and $3.38 \%$, respectively. The TSD indicator 33 showed that the trade-off/synergy relationships and their magnitudes were spatially 34 heterogeneous. The coefficients of the natural and socioeconomic factors obtained from 35 the GWR indicated that their impacts on the trade-offs/synergies vary spatiotemporally. 36 The impact factors had both positive and negative effects on the trade-offs/synergies. 37 The values of $\mathrm{R}^{2}$ and AIC implied that the selected factors had significant explanatory 38 power for the trade-off/synergy relationships between paired ESs. The findings could 39 improve the understanding of the spatiotemporal dynamics of trade-offs/synergies and 40 their spatially heterogeneous correlations with related factors.

\section{$41 \quad$ Keywords}

42 Ecosystem service, trade-off/synergy, TSD indicator, driving factor, spatially 43 heterogeneous, Yangtze River Delta region

\section{Declarations}

Not applicable

\section{Funding}

This work was supported by National Natural Science Foundation of China [grant number 41801197]; and China Postdoctoral Science Foundation [grant number

2019M652027].

\section{Conflicts of interest}

$51 \quad$ No 


\section{Author contributions}

53 All authors contributed to the study conception and design. Material preparation, data

54 collection and analysis were performed by [Cheng Li], [Jie Zhao] and[Wenfu Yang].

55 The first draft of the manuscript was written by [Cheng Li] and all authors commented 56 on previous versions of the manuscript. All authors read and approved the final 57 manuscript.

\section{Introduction}

Ecosystem services (ESs) refer to the products and services obtained from ecosystems. ESs are the basis of human survival and closely related to human wellbeing. As

61 evidenced by the Millennium Ecosystem Assessment (MEA), the loss of ESs in recent 62 decades directly threatens regional and global ecological security (MEA 2005), and this worsening trend is likely to continue in the future due to the increasing intensity of human activities (Zhou et al. 2018). In the process of pursuing socioeconomic benefits, human beings often neglect the trade-off between ESs, which leads to an improvement in one ES at the expense of other ESs, thus threatening the stability and security of ecosystems and significantly influencing human wellbeing (Feng et al. 2017). Ecosystem management should not only pursue single ecosystem service benefits but also consider the balance among multiple ESs to maximize the overall benefits and promote regional sustainable development. The importance and urgency of understanding the complex interactions among multiple ESs have been widely

72 recognized by ecosystem managers and researchers (Groot et al. 2018; Sherrouse et al. 73 2017; Xu et al. 2018). Many efforts have been made to describe and assess changes in 74 ESs and their complex interactions (trade-offs and synergies) as well as the urbanization 75 process and land cover changes (Zheng et al. 2016; Lauf et al. 2014; Sherrouse et al. 76 2017). Previous studies on ESs found that trade-off relationships are ubiquitous 77 (Langner et al. 2017; Darvill and Lindo 2016), for example, consider the trade-off 
between services resulting in the provision of a good (food production, wood production) and regulation services (soil conservation, water purification, regional biodiversity maintenance). Prior findings suggest that ecosystem management should coordinate various ESs to promote their overall benefits (Landuyt et al. 2016; Feng et al. 2020).

The identification of the trade-off/synergy relationships that exist between ESs can improve the effectiveness of ecological management (Goldstein et al. 2012; Baró et al. 2017). Over the past few years, numerous studies on trade-offs/synergies have focused on the identification and expression of the types of relationships that exist between multiple ESs using different methods. At present, research involving a trade-off/synergy analysis is mainly conducted using statistical methods (Washbourne et al. 2020; Zhou et al. 2017), spatial mapping (Haase et al. 2012), and scenario analysis (Wu et al. 2019; Asadolahi et al. 2018). For instance, Braun et al (2018) applied Pearson correlation analysis to identify the various types of relationships that exist between ESs; Xu et al (2018) used spatial overlapping and Spearman's rank correlation to analyze the relationships among ESs; Kubiszewski et al (2017) adopted scenario analysis to determine the trade-offs/synergies that exist between ESs; and Zheng et al (2016) used radar graphs to represent the trade-off/synergy relationships. These methods have enhanced the understanding of the trade-offs/synergies that exist among ESs. However, qualitative analyses of the trade-off relationships cannot measure the magnitudes of the effects of the related factors on the trade-off/synergy relationship, which is required for effective ecosystem management and planning (Bennett et al. 2009; Castro et al. 2014). The potential nonlinear characteristics of the trade-offs/synergies between ESs cannot be adequately addressed using qualitative methods. Therefore, quantitative research is urgently needed to analyze the trade-offs that exist among ESs. Some scholars tried to develop indicators to analyze these trade-offs. Laterra et al (2012) used the total ecosystem services (TES) index to quantify the interrelationships that exist among 
105 multiple ESs; Bradford and D'Amato (2012) used the root mean square error (RMSE),

106 a statistical method, to evaluate the trade-off relationships among multiple ESs. Pan et

107 al (2013) quantified the trade-off relationships among ESs by proposing the Ecosystem

108 Trade-off (ETO) index. However, the temporal scale effect of the trade-offs/synergies

109 among ESs was not considered in previous studies. Furthermore, these indicators

110 cannot reveal how the variations in multiple natural and socioeconomic factors affect

111 the interactions between ESs over a specific period. Thus, the quantitative and spatial

112 nature of these trade-offs/synergies is strongly limited.

113 Fully understanding how influencing factors affect ESs and their trade-offs/synergies

114 is a prerequisite for effective and targeted regional planning (Locatelli et al. 2014).

115 Therefore, it is urgent to identify the factors of the interactions that exist among ES's

116 relationships. By understanding the related factors and their effects on trade-

117 offs/synergies, we can coordinate the trade-offs and improve the synergies between ESs

118 (Zhang et al. 2020). Several studies have argued that the understanding of ES trade-

119 offs/synergies is insufficient without carefully considering and analyzing the driving

120 mechanisms that underlie ES relationships (Dade et al. 2018; Ndong et al. 2020).

121 Although many studies have been carried out to investigate the trade-off and synergy

122 relationships and their spatiotemporal changes, there is still little known about the

123 factors of these complex interactions. The dynamics of ESs and the related trade-

124 off/synergy relationships are complicated processes that involve various natural and

125 socioeconomic variables. In prior studies, the relationships between influencing factors

126 and the associated trade-offs/synergies were commonly analyzed using qualitative

127 methods such as by comparing scenarios (Zheng et al. 2016; Lauf et al. 2014; He et al.

128 2020). The question of how and to what extent the influencing factors affect trade-

129 offs/synergies remains poorly understood. To address these gaps, in this study,

130 correlation analysis techniques such as Pearson correlation (Zhong et al. 2020),

131 redundancy analysis (RDA) (Feng et al. 2017), and multivariate regression trees 
132 (Ndong et al. 2020) were applied to explain the global relationships among ES trade-

133 offs/synergies and the related factors without considering spatial heterogeneity. It is 134 recognized that the trade-off relationships among ESs are affected by spatial 135 heterogeneity. For example, in South Africa, a trade-off between carbon sequestration 136 and freshwater supply was found (Chisholm 2010), while research on the Baiyangdian 137 River Basin found a synergistic relationship between these two variables (Bai et al. 138 2013). Global relationships reveal information only about the average conditions and 139 might consequently overlook location-specific impacts (Fotheringham and Brunsdon 140 1999; Su et al. 2014). If we ignore spatial heterogeneity, errors might arise in the results 141 of analyses on the impacts of influencing factors on ES interactions, increasing 142 uncertainty about ES management policies (Zhang et al. 2020). It is therefore crucial to

143 explore the spatiotemporally varying relationships between trade-offs/synergies and the 144 related factors.

145 The Yangtze River Delta (YRD) region is an economically developed and densely 146 populated area in China that is experiencing serious ecological degradation and 147 environmental pollution. This paper aims to partly address this knowledge gap by using 148 the YRD as the study area and investigating the spatiotemporal changes in the trade149 offs/synergies among ESs and their spatial heterogeneous correlation with the related

150 factors. Three aspects are of particular interest: (1) the dynamics of trade-offs/synergies 151 that exist among ESs in the YRD region; (2) the spatially heterogeneous relationships 152 that exist between the influencing factors and trade-offs/synergies; and (3) the 153 implications of coordinating ESs to achieve sustainable development for ecosystem 154 management.

155 2. Material and methods

$156 \quad 2.1$ Study area

157 In this paper, the YRD region refers to associated urban agglomeration discussed in the 
"Yangtze River Delta Urban Agglomeration Development Plan" approved by the State

159 Council in May 2016. The YRD region is located in a subtropical monsoon climate 160 zone, with annual precipitation of 800-1600 mm. As shown in Fig. 1, the YRD region 161 includes 26 cities, including Shanghai, Nanjing, Hangzhou, Hefei, etc. The area of the 162 whole region is $211,700 \mathrm{~km}^{2}$, accounting for $2.1 \%$ of the total land area of China.

163 The YRD region is one of the regions with the most rapid economic and urbanization 164 development in China. Changes in land use have significantly changed the structure 165 and pattern of regional ecosystems, and many ecological environmental risks related to 166 water regulation, air purification, and climate regulation are becoming increasingly 167 severe. Because trade-offs exist between ESs, the increase in the output of food 168 production and wood production have led to the decline of WP and soil and have 169 adversely affected conservation, leisure, recreation and other regulations, support 170 services and cultural services. These problems are the result of the trade-offs that exist 171 between ESs due to the influence of human activities and natural factors. The 172 contradiction between regional socioeconomic development and the protection of the 173 ecological environment has become the main limiting factor that restricts the 174 coordinated development of the YRD region and has a certain negative impact on 175 human wellbeing. Due to socioeconomic development and the expansion of cities, the 176 magnitude of ES trade-offs will continue to increase.

177 Therefore, the quantitative measurement of the spatiotemporal dynamics in the patterns 178 of the trade-offs/synergies in the YRD and identification of the spatially heterogeneous 179 effects of influencing factors on trade-offs/synergies in the YRD region may not only 180 enrich research on ESs but also provide a scientific basis for optimizing ecosystem 181 management and regional planning. 


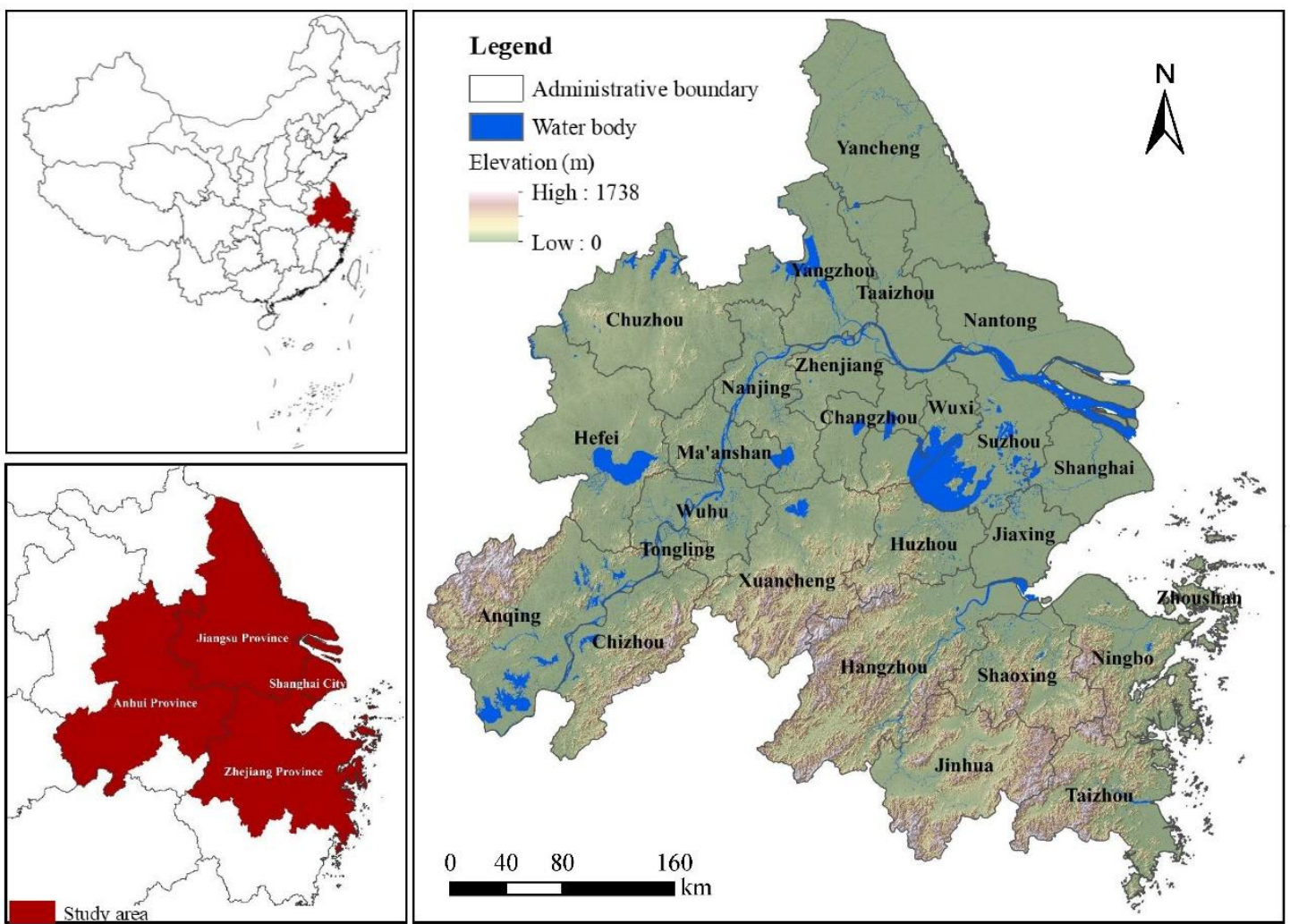

183 Fig. 1 The YRD

$184 \quad 2.2$ Data

185 The following data were used in this study: (1) Land cover data on the YRD region for 1862005 and 2015 with a resolution of $30 \mathrm{~m}$ were obtained from the Data Centre for 187 Resources and Environmental Sciences, Chinese Academy of Sciences (RESDC) 188 (http://www.resdc.cn/Default.aspx). Land cover was reclassified into six categories 189 based on the data: cultivated land, forestland, grassland, water bodies, built-up land, 190 and unused land. (2) Meteorological data, including information on precipitation, total 191 solar radiation and the temperature in the YRD region from 2005 to 2015 , were derived

192 from the China Meteorological Data Service Centre (http://data.cma.cn/). (3) Soil 193 property data, including soil depth and the content percentage of sand, clay, silt and 194 organic matter at the scale of 1:1,000,000, were obtained from the Harmonized World

195 Soil Database version 1.1 (HWSD). (4) Digital elevation model (DEM) data for the 196 YRD region with a resolution of $30 \mathrm{~m}$ were obtained from the Geospatial Data Cloud 
(http://www.gscloud.cn/). (5) Socioeconomic data, including information on the gross

198 domestic product (GDP) and population of the YRD region in 2005 and 2015, were

199 obtained from the statistical yearbook of 26 cities in the YRD region. In this study, 200 spatial data were projected to the WGS_1984_Albers coordination system, and all 201 raster data were resampled to a resolution of $100 \mathrm{~m}$.

202 This study was divided into the following steps: (1) the estimation of ESs; (2) the 203 measurement of the trade-offs/synergies among ESs during the study period; and (3) 204 the estimation of the correlation between trade-off/synergy and multiple related factors. 205 The method used in this study is presented in the following:

\subsection{Estimation of ESs}

207 In this study, we identified four key types of ESs with consideration of the following 208 criteria: (1) The selected ESs should be strongly related to human wellbeing in the YRD 209 region. (2) The data needed to calculate the selected ESs should be available. (3) The 210 selected ESs should be significantly influenced by human activities and socioeconomic 211 development. (4) The coordination of the selected ESs should be important for regional 212 sustainable development. Based on these criteria, three key ES indicators were selected 213 for the YRD region: carbon storage (CS), water purification (WP), and biodiversity 214 conservation (BC). These ESs are significantly related to human wellbeing and are 215 important for the ecological environment. Their importance increases in the YRD 216 region due to rapid socioeconomic development.

217 By using InVEST, the spatial patterns of CS, WP, and BC were quantitatively estimated. 218 The calculations used for the parameters required by the model are shown in Table 1. A 219 carbon storage and sequestration model was used to estimate CS based on four types of 220 carbon pools (aboveground biomass, belowground biomass, the soil and dead organic 221 matter). WP was evaluated in terms of nitrogen export by adopting a nutrient delivery 222 ratio model. A higher nitrogen export value indicates a lower level of WP. BC was 
224 types and threats (Zhang et al., 2018).

225 Table 1. Methods and calculations used to estimate the ESs

\begin{tabular}{|c|c|c|}
\hline ES & Method & Formula and variable description \\
\hline $\begin{array}{l}\text { Carbon Storage } \\
\text { (CS) }\end{array}$ & $\begin{array}{l}\text { InVEST Carbon } \\
\text { Storage and } \\
\text { Sequestration model } \\
()\end{array}$ & $\begin{array}{l}C S=C_{\text {above }}+C_{\text {below }}+C_{\text {soil }}+C_{\text {dead }} \\
C_{\text {above }}: \text { above ground biomass carbon stocks; } C_{\text {below }} \text { :below } \\
\text { ground biomass carbon stocks; } C_{\text {soil }} \text { : soil carbon stocks; } C_{\text {dead }} \text { : } \\
\text { dead organic matter carbon stocks. The biomass carbon density } \\
\text { for the different land use types was derived from the results of a } \\
\text { relevant study (Chuai et al. } 2013 \text { ) (Table A.1) }\end{array}$ \\
\hline $\begin{array}{l}\text { Water Purification } \\
\text { (WP) }\end{array}$ & $\begin{array}{l}\text { InVEST nutrient } \\
\text { delivery model }\end{array}$ & $\begin{array}{l}A L V_{x}=H S S_{x} \times \text { pol }_{x} \\
H S S_{x}=\frac{\lambda_{x}}{\lambda_{w}} \\
\lambda_{x}=\log \left(\sum_{U} Y_{U}\right) \\
A L V_{x}: \text { adjusted nitrogen export value for pixel } \mathrm{x} ; H S S_{x} \text { : } \\
\text { hydrological sensitivity score for pixel } \mathrm{x} ; \text { pol } l_{x}: \text { export coefficient } \\
\text { for pixel x. } \lambda_{x}: \text { runoff index for grid cell } \mathrm{x} ; \lambda_{w}: \text { mean runoff } \\
\text { index in the watershed; } \sum_{U} Y_{U}: \text { sum of the water yield of grid cell } \\
\text { along the flow path above grid cell x. The biophysical parameters } \\
\text { for water purification was presented in Table A.2. }\end{array}$ \\
\hline $\begin{array}{l}\text { Biodiversity } \\
\text { Conservation } \\
\text { (BC) }\end{array}$ & InVEST HQ model & $\begin{array}{l}i_{r x y}=1-\left(\frac{d_{x y}}{d_{r m a x}}\right) \text { if linear } \\
i_{r x y}=\exp \left(-\left(\frac{2.99}{d_{r m a x}}\right) d_{x y}\right) \text { if exponential } \\
D_{x j}=\sum_{r=1}^{R} \sum_{y=1}^{Y_{r}}\left(\frac{w_{r}}{\sum_{r=1}^{R} w_{r}}\right) r_{y} \times i_{r x y} \times \beta_{x} \times S_{j r} \\
Q_{x j}=H_{j} \times\left(1-D_{x j}\right) \\
Q_{x j}: \text { HQ of land-use type } \mathrm{j} ; H_{j}: \text { the habitat suitability of land-use } \\
\text { type } \mathrm{j} ; D_{x j}: \text { total threat level in a grid cell } \mathrm{x} \text { with land-use type } \mathrm{j} \text {; } \\
r_{y}: \text { intensity of the threat within the cell y; } w_{r}: \text { relative impact of } \\
\text { threat } \mathrm{r} ; \beta_{x}: \text { level of accessibility in grid cell } \mathrm{x} ; S_{j r} \text { : sensitivity of } \\
\text { land-use type } \mathrm{j} \text { to threat } \mathrm{r} ; i_{r x y}: \text { impact of threat } \mathrm{r} \text { from grid cell } \\
\mathrm{y} \text { on the habitat in grid cell } \mathrm{x} ; d_{x y}: \text { linear distance between grid } \\
\text { cells x and y; } d_{r m a x}: \text { maximum effective distance of the threat. } \\
\text { The parameters used in the model were presented in Table A.3. }\end{array}$ \\
\hline
\end{tabular}


Spearman correlation analysis was employed to explore the relationships among ESs at 228 the county scale based on changes in the ESs from 2000 to 2015. If the Spearman correlation coefficient for two services is higher than 0 , then a synergistic relationship 230 exists; otherwise, a trade-off relationship exists.

231 An innovative indicator, the trade-off/synergy degree (TSD), was proposed and applied 232 to further explore the magnitudes and spatial patterns of trade-off/synergy relationships 233 among the ESs.

234 The TSD indicator for ES $i$ and $\operatorname{ES} j\left(T S D_{i, j}\right)$ over the periods of $t 2$ and $t 1$ was 235 calculated with Eq. (1):

$T S D_{i, j}^{t 2-t 1}=\left\{\begin{array}{cc}0 & \left(\Delta E S_{i}^{t 2-t 1} \times \Delta E S_{j}^{t 2-t 1}=0\right) \\ \sqrt{\left(\left(\Delta E S_{i}^{t 2-t 1}\right)^{2}+\left(\Delta E S_{j}^{t 2-t 1}\right)^{2}\right) / 2} & \left(\Delta E S_{i}^{t 2-t 1} \times \Delta E S_{j}^{t 2-t 1}>0\right) \\ -\sqrt{\left(\left(\Delta E S_{i}^{t 2-t 1}\right)^{2}+\left(\Delta E S_{j}^{t 2-t 1}\right)^{2}\right) / 2} & \left(\Delta E S_{i}^{t 2-t 1} \times \Delta E S_{j}^{t 2-t 1}<0\right)\end{array}\right.$

237 where $\Delta E S_{i}^{t 2-t 1}$ and $\Delta E S_{j}^{t 2-t 1}$ are the relative changes in ESs $i$ and $j$ over the period $238 t 2-t 1$, respectively, and are calculated as follows: $\left\{\begin{array}{l}\Delta E S_{i}^{t 2-t 1}=\left(E S_{i}^{t 2}-E S_{i}^{t 1}\right) / E S_{i}^{t 1} \\ \Delta E S_{j}^{t 2-t 1}=\left(E S_{i}^{t 2}-E S_{j}^{t 1}\right) / E S_{j}^{t 1}\end{array}\right.$

240 where $E S_{i}^{t 2}$ and $E S_{i}^{t 1}$ represent the value of ES $i$ at time points $t 2$ and $t 1$, 241 respectively. As shown in Eq. (1), if $\Delta E S_{i}^{t 2-t 1} \times \Delta E S_{j}^{t 2-t 1}=0$, then $T S D_{i, j}^{t 2-t 1}=0$, 242 implying that no trade-off/synergy relationship exists between $E S_{i}$ and $E S_{j}$. If $243 \Delta E S_{i}^{t 2-t 1} \times \Delta E S_{j}^{t 2-t 1}>0$, a synergy relationship exists between $E S_{i}$ and $E S_{j}$, and the 244 level of synergy can be measured by $\sqrt{\left(\left(\Delta E S_{i}^{t 2-t 1}\right)^{2}+\left(\Delta E S_{j}^{t 2-t 1}\right)^{2}\right) / 2}$. If $\Delta E S_{i}^{t 2-t 1} \times$ $245 \Delta E S_{j}^{t 2-t 1}<0$, then a trade-off relationship exists between the two ESs, and the level of 246 the trade-off can be measured by $-\sqrt{\left(\left(\Delta E S_{i}^{t 2-t 1}\right)^{2}+\left(\Delta E S_{j}^{t 2-t 1}\right)^{2}\right) / 2}$.

247 Before conducting spatial regression analysis, the global Moran's I index was first 248 applied to detect the spatial dependence of the trade-offs/synergies among the ESs. At 
a given significance level, Moran's I value ranges from -1 to 1 . A value closer to 1

250 implies that the trade-off/synergy relationship in a specific area has a trend similar to 251 that of the surrounding areas. A value closer to -1 suggests that the trade-off/synergy 252 relationship in a specific area has a trend that is dissimilar to that of the surrounding 253 areas. If Moran's I is 0 , then the trend of the trade-off/synergy relationship is randomly 254 distributed. The equation used to calculate the global Moran's I is as follows (Anselin 255 1995):

$256 \quad I=N \times\left(\sum_{i=1}^{n} \sum_{j=1}^{n} W_{i j}\left(Y_{i}-\bar{Y}\right)\left(Y_{j}-\bar{Y}\right)\right) /\left(\left(\sum_{i=1}^{n} \sum_{j=1}^{n} W_{i j}\right) \sum_{i=1}^{n}\left(Y_{i}-\bar{Y}\right)^{2}\right)$

257 where $I$ is Moran's I index; $N$ is the number of units; $Y_{i}$ and $Y_{j}$ indicate the trade258 off/synergy values for ES $i$ and ES $j$; and $\bar{Y}$ denotes the average level of the trade259 off/synergy values of the ESs. $W_{i j}$ represents the row-standardized contiguity matrix.

\subsection{Evaluation of the impacts of factors on ESS trade-offs/synergies}

261 With consideration of natural and socioeconomic influences, seven potential 262 influencing factors were selected: elevation (ELE), changes in annual average 263 precipitation (PRE), changes in annual average temperature (TEM), changes in GDP 264 (GDP), changes in population density (POP), and changes in the proportion of built-up 265 land (BUL).

266 Understanding how the influencing factors have contributed to the variations in the 267 trade-offs/synergies among ESs is crucial for effective ecosystem management. 268 Multiple linear regression (MLR) is one of the regression methods commonly used for 269 exploring the relationships between multiple explanatory factors and independent 270 variables (Yu et al. 2020). Taking the study area as a whole, MLR can be used to explore 271 the average regression coefficient by identifying a global relationship. The MLR used 272 in this study is expressed in Eq (4):

$273 y_{i}=\beta_{0}+\sum_{k=1}^{i} \beta_{k} x_{i k}+\varepsilon$ 
274 where $y_{i}$ is the estimated TSD value; $\beta_{0}$ and $\beta_{k}$ represent the intercept and 275 regression coefficients of independent variable $k$, respectively; $x_{i k}$ is the value of 276 independent variable $k$ at unit $i$; and $\varepsilon$ is the random error term for unit $i$.

277 A geographically weighted regression (GWR) model can estimate a location-specific 278 regression coefficient for each unit in the study area by considering spatially varying 279 relationships that exist between the dependent and independent variables. In this study, 280 a GWR model was adopted to investigate the relationships between the related factors 281 and the trade-offs/synergies while considering spatial heterogeneity. The formula used 282 for the GWR is similar to that used for the MLR, except the former takes spatial 283 heterogeneity into consideration. The GWR can be expressed as follows (Fotheringham 284 et al. 1997):

$y_{i}=\beta_{0}\left(u_{i}, v_{i}\right)+\sum_{k=1}^{i} \beta_{k}\left(u_{i}, v_{i}\right) x_{i k}+\varepsilon_{i}$

286 where $y_{i}$ represents the TSD value for unit $i ;\left(u_{i}, v_{i}\right)$ represents the coordinates of 287 unit $i ; \beta_{0}\left(u_{i}, v_{i}\right)$ is the constant term estimated for unit $i$; and $\beta_{k}\left(u_{i}, v_{i}\right)$ is the 288 estimated regression coefficient of factor $k$ at unit $i . x_{i k}$ represents the value of 289 independent variable $k$ that could explain TSD at unit $i ; \varepsilon_{i}$ is the random error term 290 for unit $i$. The regression coefficients of each unit are estimated by weighting all units 291 around unit $i$. The units closer to unit $i$ have a stronger impact on the estimated 292 coefficient. The Gaussian kernel was selected to calculate the spatial weighting:

$293 w_{i j}=\exp \left(\frac{-d_{i j}^{2}}{h^{2}}\right)$

294 where $w_{i j}$ is the weight of unit $j$ for unit $i . d_{i j}$ represents the Euclidean distance 295 between unit $i$ and unit $j . h$ is the kernel bandwidth, which determines the range of 296 spatial dependency. In this study, we selected the optimal bandwidth identified by the 297 Akaike's information criterion (AIC) method for the purposes of minimizing the AIC 298 value: the estimated results with lower AIC values better reflect reality. 
299 The performance of the regression models (MLR and GWR) can be measured and 300 compared by considering $\mathrm{R}^{2}$ and AIC. $\mathrm{R}^{2}$ is the square of the correlation coefficient, 301 indicating the degree of agreement between the estimated value and the observed value. 302 AIC is not an absolute goodness of fit, but it can be used to effectively compare several 303 different models. A difference between the AIC values of two models higher than 3 304 suggests that there is a significant difference between the two models. A more suitable 305 model, which is assessed by its capability to better explain the variations in the 306 dependent variables, tends to have a higher $\mathrm{R}^{2}$ and lower AIC.

\subsection{Spatial patterns of ESs}

310 As shown in Fig. 2, forestland is mainly located in the southern part of the YRD region.

311 High-intensity built-up land is concentrated along the Yangtze River. Cultivated land is 312 mainly distributed in the northern part of the YRD region. Cultivated land accounted 313 for $47.63 \%$ of the total area, the largest proportion of the YRD region, in 2015. Built314 up land accounted for $12.75 \%$ of the total area in 2015.

315 From 2005 to 2015 , built-up land increased by $7760.21 \mathrm{~km}^{2}$, which accounted for the 316 largest proportion of change in land cover. In contrast, cultivated land, forestland, 317 grassland and wetland decreased. Cultivated land decreased significantly from $318107,224.31 \mathrm{~km}^{2}$ to $100,253.03 \mathrm{~km}^{2}$ over ten years due to rapid urbanization. A large 319 proportion of the decrease in cultivated land was caused by newly developed built-up 320 land. Forestland and wetland decreased by $502.03 \mathrm{~km}^{2}$ and $400.31 \mathrm{~km}^{2}$ from 2005 to 3212015 , respectively. 

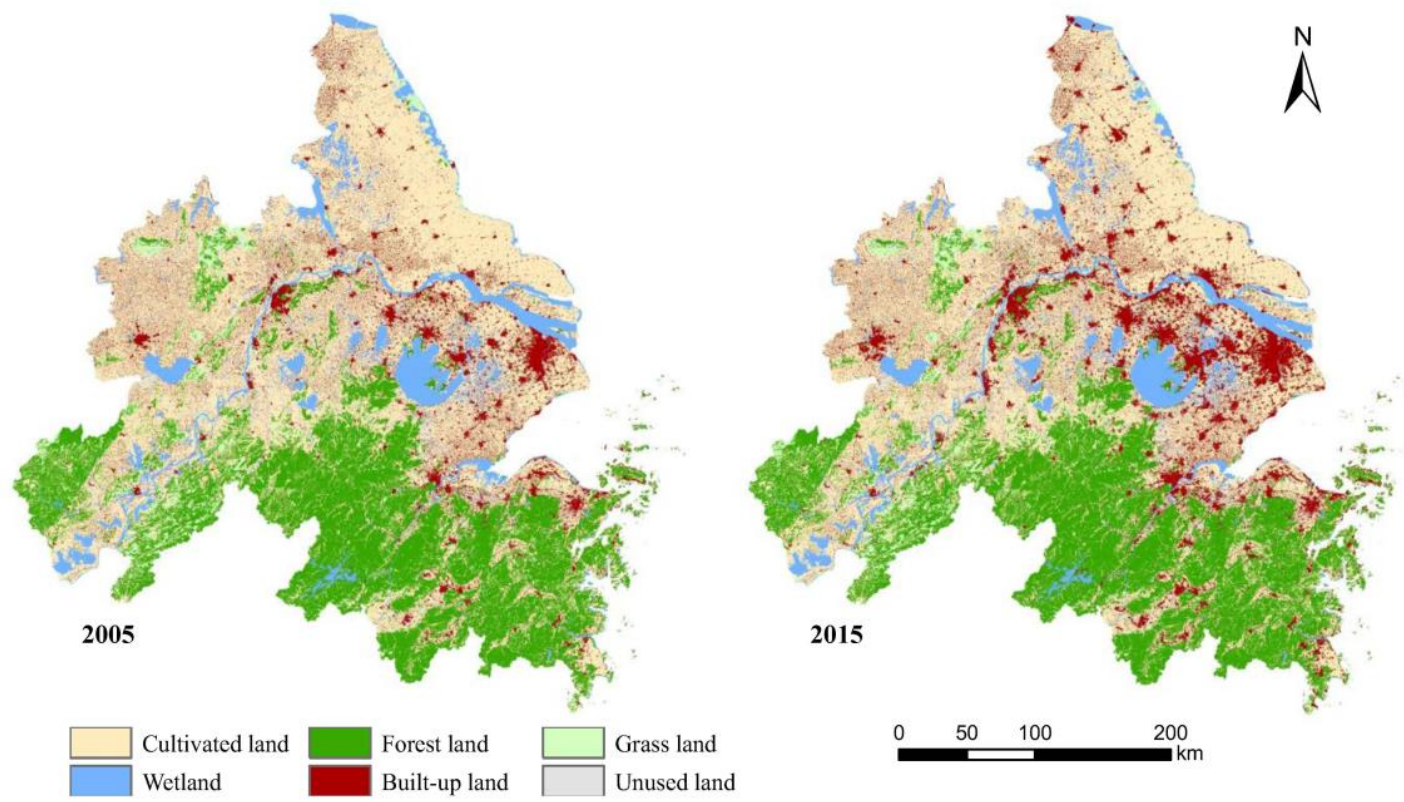

323 Fig. 2 Land cover map of the YRD region in 2005 and 2015.

325 Table 2. Area of various land cover types in the YRD region in 2005 and $2015\left(\mathrm{~km}^{2}\right)$.

\begin{tabular}{|l|l|l|l|l|l|l|}
\hline & Cultivated land & Forestland & Grassland & Wetland & Built-up land & Unused land \\
\hline 2005 & 107224.31 & 57424 & 7377.18 & 19340.63 & 19072.64 & 34.16 \\
\hline Proportion & 50.94 & 27.28 & 3.51 & 9.19 & 9.06 & 0.02 \\
\hline 2015 & 100253.03 & 56922 & 7291.3 & 18940.32 & 26832.85 & 233.45 \\
\hline Proportion & 47.63 & 27.05 & 3.46 & 9.00 & 12.75 & 0.11 \\
\hline $2005-2015$ & -6971.28 & -502.03 & -85.88 & -400.31 & 7760.21 & 199.29 \\
\hline
\end{tabular}

326 Along with land cover changes in the YRD region, the selected ESs also varied over

327 the study period. The overall magnitude of CS, WP (measured by nitrogen export), and

328 BC (measured by HQ) in the YRD region decreased from 2005 to 2015. CS decreased 329 marginally from $5.028 \times 10^{8}$ to $4.969 \times 10^{8} \mathrm{Mg}$. The total amount of WP decreased from

$3303.891 \times 10^{7} \mathrm{~kg}$ to $3.794 \times 10^{7} \mathrm{~kg}$. The average value for $\mathrm{BC}$ shows a declining trend, with

331 the value decreasing from 0.385 in 2005 to 0.372 in 2015 .

332 Table 3. The total amount of ESs in the YRD region in 2005 and 2015.

\begin{tabular}{|c|c|c|c|}
\hline & $\mathbf{C S} \mathbf{( M g )}$ & $\mathbf{W P}(\mathbf{k g})$ & BC \\
\hline $\mathbf{2 0 0 5}$ & $5.028 \times 10^{8}$ & $3.891 \times 10^{7}$ & 0.385 \\
\hline $\mathbf{2 0 1 5}$ & $4.969 \times 10^{8}$ & $3.794 \times 10^{7}$ & 0.372 \\
\hline $\mathbf{2 0 0 5 - 2 0 1 5}$ & $-1.17 \%$ & $-2.49 \%$ & $-3.38 \%$ \\
\hline
\end{tabular}


333 There is significant spatial heterogeneity in CS, WP, and BC in 2005 and 2015. As

334 shown in Fig. 3, the high-provision areas for CS were mainly distributed in the southern 335 mountainous area of the YRD, while the lower CS values were located in urban areas, 336 where a large amount of non-built-up land had changed to built-up land. The high337 provision areas for WP were mainly distributed in the northern area. WP in the YRD 338 shows a gradual decreasing trend from southeast to northwest, which is consistent with 339 the spatial patterns of the proportion of cultivated land. High values of $\mathrm{BC}$ were found 340 in the south areas, which are at higher elevations, while low value areas were mainly 341 distributed in the north area. This result can be explained by the fact that areas with 342 high elevations are mountainous with dense vegetation and rich biodiversity. In these 343 areas, the natural environment, such as mountains, face fewer threats.
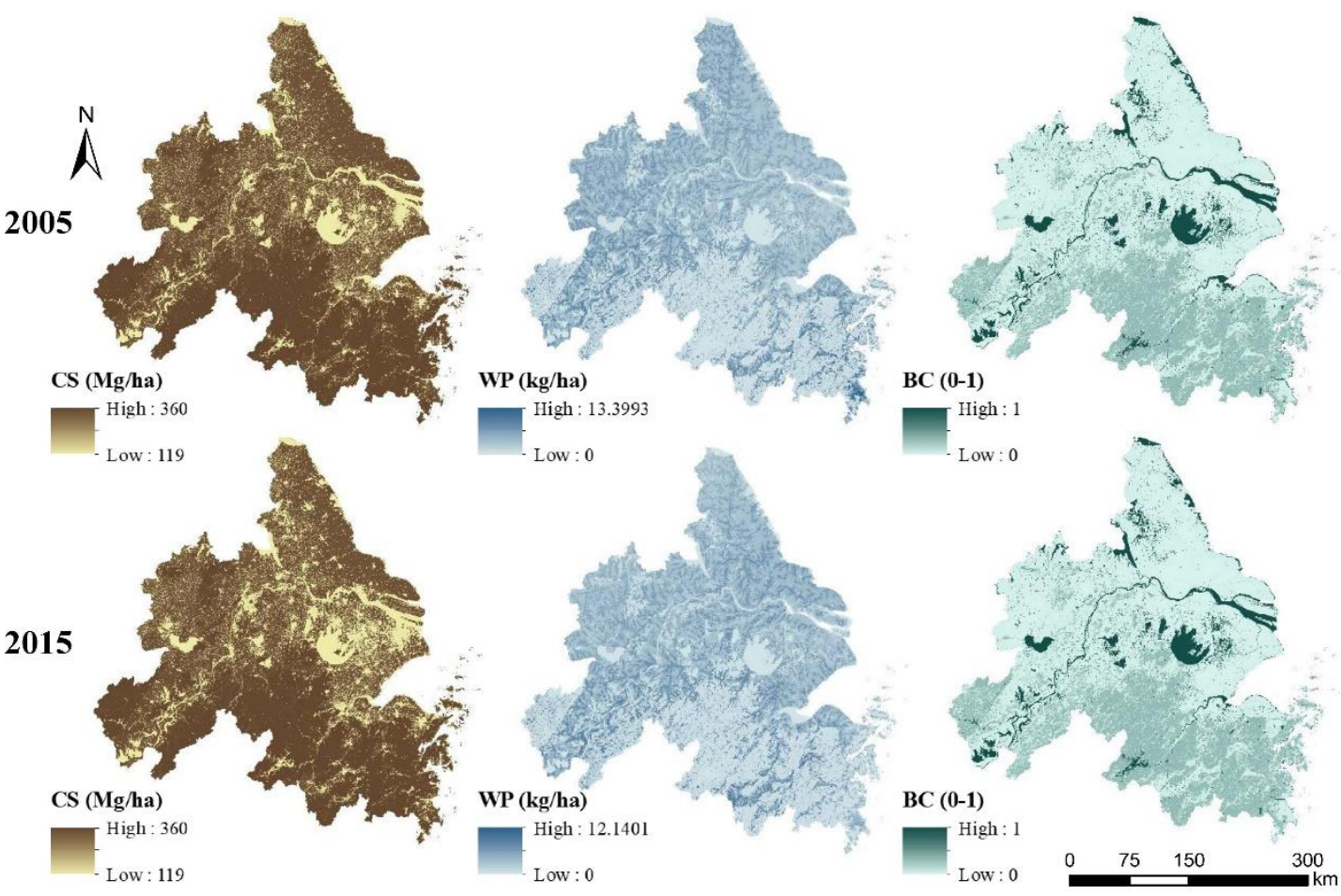

345 Fig. 3 Spatial patterns of ESs in the YRD region at the grid scale (CS: carbon storage; CP: crop production; WP: water purification; BC: biodiversity conservation).

347 The majority of counties (157 out of 160 counties) in the YRD region show a decreasing 348 trend in CS from 2005-2015 (Fig. 4). Among these cities, Kunshan (Suzhou city) and 349 Jiading (Shanghai city) experienced the most significant decline in average CS, 
decreasing by $17.831 \mathrm{Mg} / \mathrm{ha}$ and $15.236 \mathrm{Mg} / \mathrm{ha}$, respectively. Dafeng, Xiaoshan, and

351 Chongming showed a slight increase in average CS over the study period.

352 Overall, WP exhibited a downward trend across the YRD region. At the county level, 353 over one-half (89) of the counties in the YRD region showed that WP is increasing, 354 mainly in the eastern part of the YRD, accounting for $52.8 \%$ of the total area. Cultivated 355 land was converted to BUL. The counties exhibiting a significant decrease in WP are 356 the southeastern part of the YRD, including Wenling, Yuhuan, and Huangyan, which implies that nitrogen exports decreased remarkably over time.

358 Most of the counties (156) presented a declining trend for BC, especially the Suzhou 359 city core and Xiaoshan (Hangzhou city), decreasing by $33.3 \%$ and $18.3 \%$, respectively. 360 Only 4 counties experienced an increase from 2005-2015, mainly centralized in 361 Nantong, Chuzhou, Yangzhou, and Taaizhou cities, accounting for $4.43 \%$ of the total 362 area. The reduction in $\mathrm{BC}$ was mainly due to significant urban expansion.

363

364
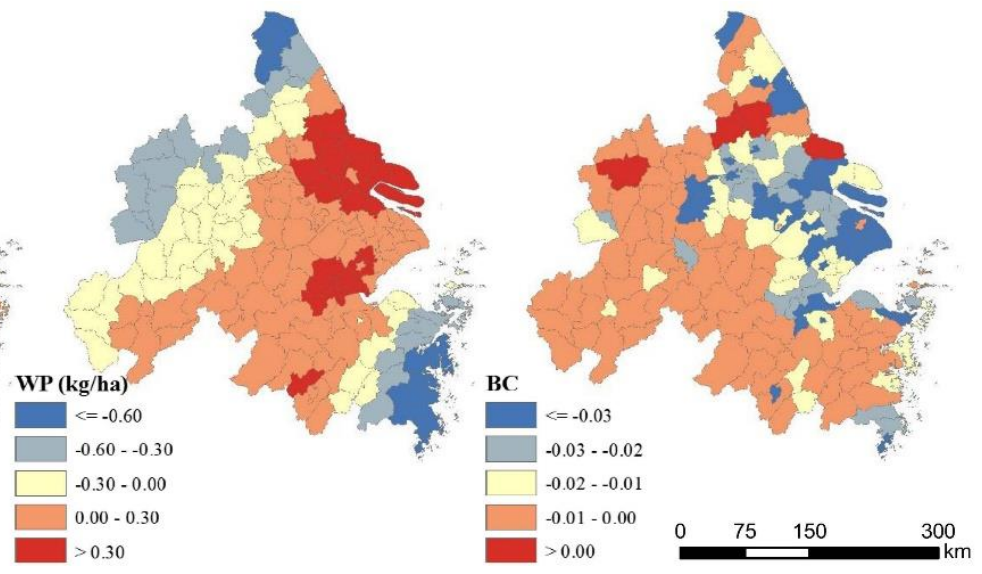

Fig. 4 Spatial patterns of ES variations at the county scale in the YRD region (CS: carbon storage; CP: crop production; WP: water purification; BC: biodiversity conservation).

\subsection{Spatiotemporal dynamics of ESs trade-offs/synergies}

We used Spearman correlation analysis to identify the trade-off/synergy relationships that exist among multiple ESs. As shown in Fig. A.1, both trade-offs and synergies were observed. We found that all three pairs of ESs (CS-WP, CS-BC, WP-BC) showed 
significant positive or negative correlations $(\mathrm{P}<0.01)$. CS was significantly positively

371 correlated with BC. This result was supported by our findings that CS increased from

3722005 to 2015, and BC decreased over this period. The trade-offs between CS/WP and

$373 \mathrm{WP} / \mathrm{BC}$ suggested that a decrease or increase in one ES could lead to an increase or

374 decrease in another ES in a specific county. CS had a strong and significant synergy

375 with BC, with a Spearman correlation coefficient larger than 0.7.

376 The TSD indicator was further applied to reveal the spatial distribution and magnitude 377 of the trade-off/synergy relationships among the ESs. In contrast to the results of the 378 Spearman correlation analysis, in this analysis, both trade-off and synergy relationships 379 were detected between paired ESs. The spatial distributions of the trade-offs/synergies 380 were significantly heterogeneous (Fig. 5).
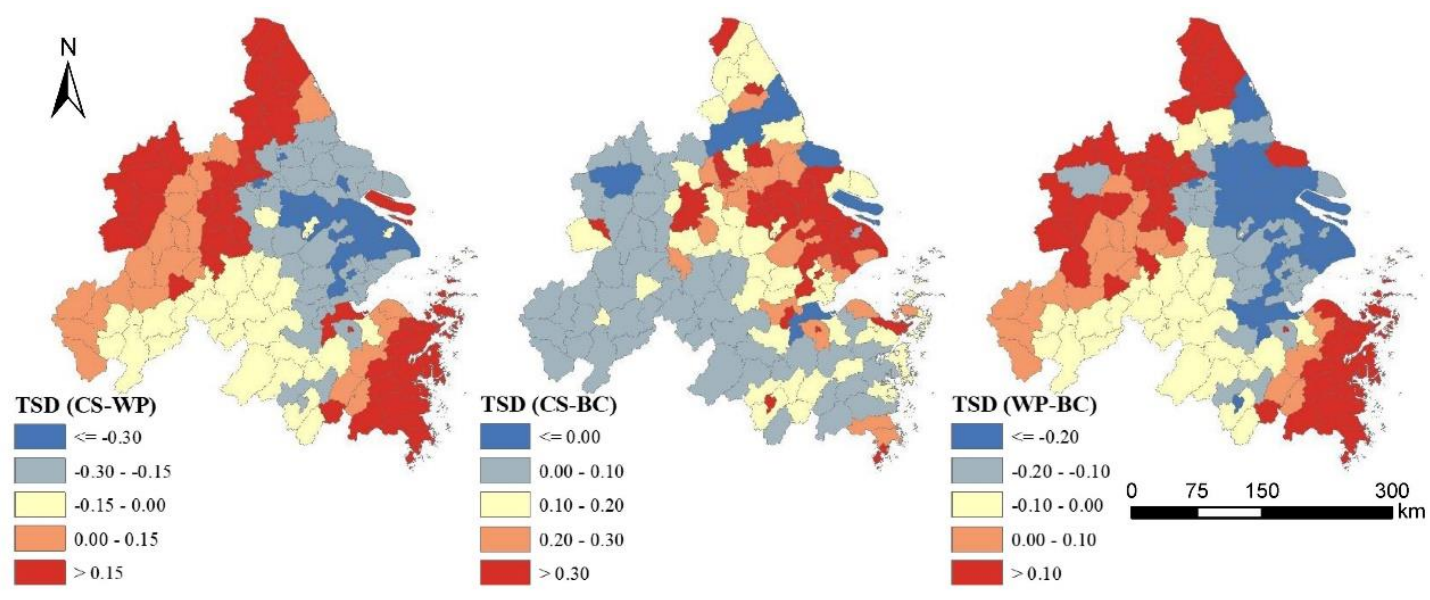

382 Fig. 5 Spatial patterns of the synergies and trade-offs (measured by TSD) among multiple ESs at the county scale in the YRD region (CS: carbon storage; CP: crop production; WP: water purification; BC: biodiversity conservation).

385 The negative TSD value for CS-WP were mainly distributed in the eastern and southwestern areas, which indicates that a decrease in CS could lead to an increase in

387 WP in these regions. This result is consistent with the previous findings of Bai et al. 388 (2020). A larger amount of ecological land, the main type of land that supports CS, was occupied by built-up land due to the rapid development in this region. Significant urban

390 expansion resulted in a decrease in CS. The loss in ecological land led to an increase in 
391 nitrogen export. Furthermore, the TSD value for CS-WP decreased gradually from the 392 eastern area to the southwestern area. In contrast, the relationship between CS and WP 393 is synergetic (TSD $>0$ ) in the southeastern and northwestern areas, and this result 394 contrasts with the implications of the Spearman correlation coefficient for CS-WP. This 395 result suggests that a decrease in CS might decrease nitrogen export. This decrease is 396 may have occurred because cultivated land was converted to built-up land, and the 397 increase in built-up land area might decrease CS. Additionally, the higher proportion of 398 built-up land produced higher nitrogen loads than other land cover classes.

399 CS and BC mainly exhibited a synergistic relationship throughout the YRD region; this 400 relationship can be attributed to high consistency in the land cover types of CS and BC. 401 For example, ecological land normally has higher values of CS and BC. However, built402 up land has a lower capacity for CS and BC. The high values for TSD were mainly 403 distributed in the eastern part of the YRD region, and the values gradually decreased 404 from the eastern area to the western area of the YRD region. The Shanghai and Suzhou405 Wuxi-Changzhou regions in the eastern area of the YRD region are the most developed 406 areas and exhibit a significant increase in built-up land to meet increasing demand for 407 socioeconomic development. Therefore, the trade-off intensity in this area is higher 408 than in other areas.

409 Similar to the spatial distribution of the TSD value for CS-WP, a large proportion of 410 counties exhibited trade-off relationships between WP and $\mathrm{BC}$ in the eastern and 411 southern areas of the YRD region, which means that the increase in nitrogen export 412 might decrease HQ. In addition, the trade-off intensity gradually decreased from the 413 eastern areas to the southern areas. This decrease may have occurred because newly 414 cultivated land occupies a large amount of ecological land, which leads to a decrease in $415 \mathrm{BC}$ and an increase in WP. Positive TSD values are observed in the northwestern and 416 southeastern areas, which indicates that the relationship between WP and BC is 417 synergistic. When WP decreases, BC will decrease. 
418 The global Moran's I for the TSD of each paired ES is presented in Table 4. The values 419 of $0.8309,0.3979$, and 0.7216 for CS-WP, CS-BC, and WP-BC, respectively, suggest 420 that the patterns of the trade-off/synergy relationships between the paired ESs were 421 spatially autocorrelated.

422 Table 4. Global Moran's I of the TSD values between paired ESs.

\begin{tabular}{|l|l|l|l|}
\hline Pairs of ESs & Moran's I & z-score & p-value \\
\hline CS-WP & 0.8309 & 11.5593 & 0.0000 \\
\hline CS-BC & 0.3979 & 5.6219 & 0.0000 \\
\hline WP-BC & 0.7216 & 10.0640 & 0.0000 \\
\hline
\end{tabular}

4233.3 The impacts of related factors on the trade-offs/synergies between ESs

424 We applied the MLR and GWR models to investigate the spatial relationships between 425 the TSD and seven natural and socioeconomic factors (ELE, PRE, TEM, GDP, POP, 426 and BUL). As shown in Table 5, the $\mathrm{R}^{2}$ values of the GWR results are larger than those 427 of the MLR model. The AIC values of the GWR are smaller than those of the MLR 428 model. In contrast to the results of the MLR model, which is a global model for 429 estimating the relationship between two variables, the GWR results provide a specific 430 coefficient for each unit. The effects of the spatial relationship between the explanatory 431 and dependent variables on the trade-offs/synergies between the ESs is explored.

432 Table 5. $\mathrm{R}^{2}$ and AIC values for the GWR and MLR models

\begin{tabular}{|l|l|l|l|l|l|l|l|}
\hline \multirow{2}{*}{ Factors } & \multirow{2}{*}{ Indicator } & \multicolumn{2}{|c|}{ CS-WP } & \multicolumn{2}{c|}{ CS-BC } & \multicolumn{2}{c|}{ WP-BC } \\
\cline { 3 - 8 } & & MLR & \multicolumn{1}{|c|}{ GWR } & \multicolumn{1}{|c|}{ MLR } & \multicolumn{1}{|c|}{ GWR } & \multicolumn{1}{c|}{ MLR } & \multicolumn{1}{c|}{ GWR } \\
\hline \multirow{3}{*}{ ELE } & $\mathrm{R}^{2}$ & 0.0137 & 0.8031 & 0.0981 & 0.3950 & 0.0213 & 0.7643 \\
\cline { 2 - 8 } & AIC & 29.9511 & -148.1661 & -55.1897 & 77.0673 & -4.8324 & -165.4915 \\
\hline \multirow{3}{*}{ PRE } & $\mathrm{R}^{2}$ & 0.5777 & 0.7456 & 0.0071 & 0.3093 & 0.6076 & 0.7444 \\
\cline { 2 - 8 } & AIC & -105.7788 & -163.5704 & -39.8081 & -74.5886 & -151.0859 & -197.8709 \\
\hline \multirow{3}{*}{ TEM } & $\mathrm{R}^{2}$ & 0.0279 & 0.7900 & 0.0063 & 0.2966 & 0.0420 & 0.7538 \\
\cline { 2 - 8 } & AIC & 27.6261 & -162.3956 & -39.6942 & -75.4645 & -8.2591 & -187.0395 \\
\hline \multirow{3}{*}{ GDP } & $\mathrm{R}^{2}$ & 0.0659 & 0.7732 & 0.0713 & 0.3445 & 0.0583 & 0.7658 \\
\cline { 2 - 8 } & AIC & 21.2469 & -140.3177 & -50.5173 & -79.4526 & -10.9957 & -168.7866 \\
\hline \multirow{3}{*}{ POP } & $\mathrm{R}^{2}$ & 0.0255 & 0.7697 & 0.0744 & 0.3252 & 0.0098 & 0.7538 \\
\cline { 2 - 8 } & AIC & 28.0298 & -132.7592 & -51.0407 & -74.8401 & -2.9728 & -155.6341 \\
\hline
\end{tabular}




\begin{tabular}{|l|l|l|l|l|l|l|l|}
\hline \multirow{3}{*}{ BUL } & $\mathrm{R}^{2}$ & 0.1786 & 0.8640 & 0.7864 & 0.8055 & 0.1597 & 0.8170 \\
\cline { 2 - 8 } & AIC & 0.6776 & -203.8839 & -285.6687 & -290.4239 & -29.2331 & -193.8583 \\
\hline \multirow{2}{*}{ FOR } & $\mathrm{R}^{2}$ & 0.0789 & 0.8606 & 0.0081 & 0.3710 & 0.0930 & 0.7789 \\
\cline { 2 - 8 } & AIC & 19.0150 & -163.1552 & -39.9697 & -83.4644 & -17.0035 & -162.4327 \\
\hline
\end{tabular}

433 Fig. 6 presents the spatial distributions of the estimated regression coefficients of the

434 influencing factors and trade-offs/synergies between paired ESs using the GWR model.

435 The effects of the explanatory factors on ES trade-offs/synergies varied spatially. Both

436 positive and negative coefficients are observed in the GWR results. A positive

437 coefficient indicates that growth in the explanatory variable could increase the TSD

438 value. In other words, the probability that the ES relationship will become more

439 synergetic will increase when the coefficient is positive. However, a negative 440 coefficient suggests that a decrease in the dependent variables could decrease the 441 probability that a synergistic relationship exists between the ESs, as evidenced by a 442 declining TSD value.

443 Elevation was positively correlated with the trade-off/synergy relationships between 444 CS and WP in the eastern part of the YRD region. This result implies that an increase 445 in elevation could enhance the synergy between CS and WP or reduce their trade-off 446 relationship in this area. In contrast, a negative effect of elevation was mainly observed 447 in the western area. 


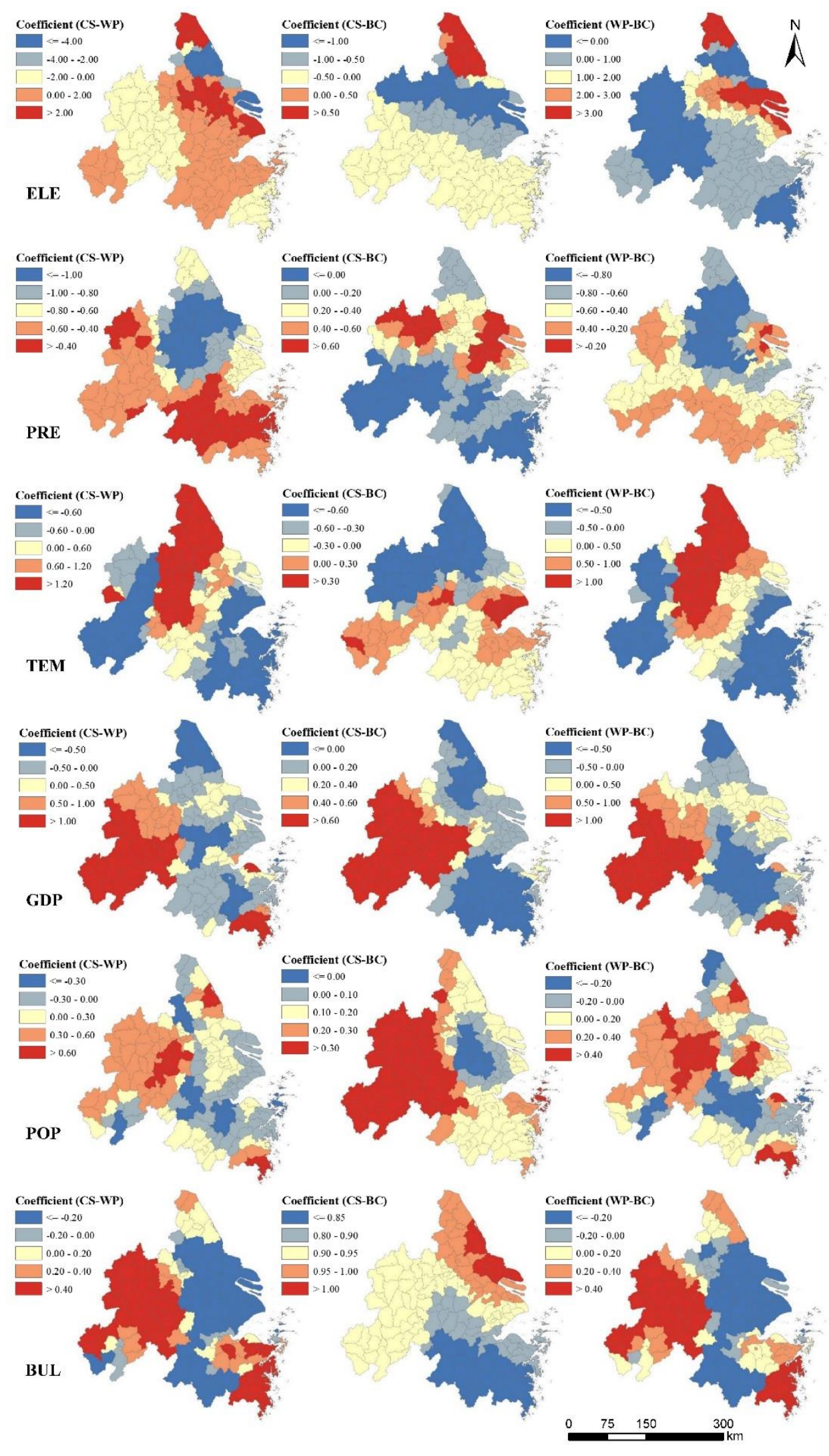

449 Fig. 6 Coefficients of the relationship between the TSD of paired ESs and six variables using 450 the GWR model. 
451 For a large area of the YRD region, there was a negative association between elevation 452 and the CS-BC relationship, which suggests that a decrease in elevation could lead to 453 an increase in synergy intensity. This result may be related to the distribution of 454 ecological land across different elevations. When there is a decrease in elevation, the 455 proportion of forest decreases and that of cultivated land and built-up land increases. 456 The urban expansion rate in this area is relatively higher than that in areas in higher 457 elevations. The changes in CS and BC are relatively significant; thus, synergy was 458 enhanced.

459 Precipitation is an important variable of the trade-off/synergy relationships from 20054602015 (Fig. 6). Changes in precipitation had a negative effect on CS-WP and WP-BC. 461 This result implies that an increase in precipitation may either increase the trade-off 462 intensity or reduce the synergy intensity. The vegetation coverage area increased as 463 precipitation increased, CS and BC were enhanced, and WP decreased; thus, trade-off 464 intensity increased. Additionally, the effects of precipitation in the southern area of the 465 YRD region are greater than those in other areas due to its higher proportion of 466 ecological land and significantly higher levels of precipitation. The negative correlation 467 between precipitation and the trade-off/synergy intensity for CS-BC in the southern 468 area was related to the relatively slow changes in CS and $\mathrm{BC}$.

469 The changes in TEM also had significant effects on the trade-off/synergy relationships 470 between the paired ESs. Both positive and negative correlations between the 471 temperature and TSD were found across the YRD region. As presented in Fig. 6, the 472 spatial distributions of the coefficients for CS-WP and WP-BC are similar. The change 473 in TEM in the eastern and western areas exhibited a negative correlation with the trade474 off/synergy intensity of CS-WP and WP-BC. TEM had a positive effect on the TSD in 475 the central and northern areas of the YRD region. As evidenced by Singer (2003), the 476 effects of climate factors on ESs are spatially heterogeneous. 
As illustrated in Fig. 6, GDP and POP have positive and negative correlations with the trade-offs/synergies between ESs. CS-WP, CS-BC, and WP-BC have significant positive relationships with GDP and POP in the western area of the YRD region, where the intensity of human activity and the socioeconomic level are relatively weak compared those in with the eastern region. In the eastern area of the YRD region, however, an increase in GDP or POP will increase the probability that the relationships will convert to a trade-off.

The results for $\mathrm{R}^{2}$ indicate that BUL had the largest effects on the relationships between paired ESs among these factors. The changes in built-up land are negatively correlated with CS-WP and WP-BC relationships in the eastern area of the YRD region, where built-up land is concentrated and increased significantly over the study period (Fig. 6). The newly expanded built-up land occupied a larger amount of cultivated and ecological land, which led to a significant decline in CS and BC because of the loss of land cover classes that support CS and BC. In contrast, urbanization was positively correlated with nitrogen export due to heavy pollutant loads on impervious surfaces and the weak purification ability of the limited amount of vegetation coverage. In addition, BUL exhibited a positive correlation with the synergy intensity of CS-BC across the YRD region, and its effects gradually increased from southern areas to northern areas. This result implies that the synergy between CS and BC is more sensitive to changes in BUL. CS and BC are affected by a higher level of land-use consistency, and the increase in BUL could decrease the area of land cover types that support CS and BC.

\section{Discussion}

\subsection{Spatially varying trade-offs/synergies among the ESs and the underlying factors}

By understanding the spatial patterns of the ES relationships' responses to influencing factors, decision makers can regulate these factors to improve the synergy intensity and reduce unwanted trade-offs (Cord et al. 2017). Our findings show that the trade-offs 
and synergies among multiple ESs (CS, WP, and BC) were widespread in the YRD

504 region, which is in accordance with the findings of previous studies (Bai et al. 2020; 505 Xu et al. 2018; Jopke et al. 2015). However, studies concerning the spatial distribution 506 of the intensity of trade-offs/synergies are scarce. Pairwise correlation coefficients are 507 commonly used to reveal the global relationships between paired ESs (He et al. 2020; 508 Morán-Ordóñez et al. 2020). This type of analysis reflects only the magnitude of a 509 relationship and does not provide insight into the spatial patterns of a relationship. The 510 hot spots of various ESs were compared to investigate the spatial relationship between 511 two ESs. However, the results generated by hot spot comparisons do not indicate where 512 trade-offs and synergies exist. The RMSE indicator was widely adopted in previous 513 studies to measure the intensity of trade-offs for one temporal point (Bradford and 514 D'Amato 2012; Langner et al. 2017), but changes in ESs over time are not considered 515 in this indicator. Zhang et al $(2020)$ used a binary value $(0,1)$ to measure the relationship 516 by comparing the changes in ESs between two points in time. Although this type of 517 analysis can identify the ES relationships, the magnitude of the relationships is not 518 measured. Therefore, it is difficult to fully reveal the impact mechanisms of the trade519 offs/synergies. In this study, we proposed a new indicator (TSD) to quantify the 520 intensity of the trade-off/synergy relationships among ESs and their spatial 521 heterogeneity rather than their spatial homogeneity. Compared with the findings of 522 previous studies, our findings clarify the locations where trade-offs/synergies existed 523 and their intensity.

524 Our study supports the argument that the relationships between ESs can be affected by 525 natural and socioeconomic factors (Syrbe and Walz 2012). For appropriate ES 526 management, decision makers should consider not only global correlations but also the 527 spatial heterogeneity of the impacts to mitigate unwanted ES trade-offs. In contrast to 528 the findings obtained by using correlation analysis and a global regression model (Feng 529 et al. 2020; Zhong et al. 2020), our results obtained by the GWR model can reveal the 
spatial relationship between trade-offs/synergies and the related factors. The intensity of trade-off/synergy relationships was significantly affected by natural factors and socioeconomic factors. A larger number of studies have confirmed that ESs are correlated with urbanization (Baró et al. 2016). Su et al (2014) argued that the effects of urbanization on ESs are spatially heterogeneous, with the magnitude of the effects varying spatially, which is similar to our findings. However, previous studies considering topics related to the effects of influencing factors on the complex relationships that exist among multiple ESs were limited by the use of a global regression model and correlation analysis without considering spatial non-stationarity. In this study, goodness of fit tests employed to compare the MLR and GWR models were assessed using $\mathrm{R}^{2}$ and AIC. The results indicate that the GWR model has strong explanatory capability for estimating the relationships between the influencing factors and the trade-off/synergy intensity of ESs. The coefficients estimated by the GWR model correspond to a specific geographic area, and the spatially varying effects of various factors can be explored through the creation of a spatial distribution map of the GWR coefficients.

\subsection{Policy implications}

Integrating information about the trade-offs/synergies between ESs into ecological planning and management is a prerequisite for coordinating the relationship between ecological protection and socioeconomic development (Peng et al. 2017). This study quantitatively explores the influencing mechanisms of natural and socioeconomic processes on the trade-off/synergy relationships among ESs, which is helpful for developing scientific and effective ecosystem service management practices and regional planning. Recommendations for ES regulation and promotion that correspond to our results are as follows:

First, in the context of the collaborative development of the YRD region, it is crucial to 
556 enhance the implementation of precisely targeted ecological projects and refine 557 ecological management policies based on the analysis of the trade-offs/synergies among 558 ESs. In recent years, a range of ecological projects have been carried out, such as the 559 Grain for Green Project, the Natural Forest Protection Project, and Reclaiming Lake 560 from Farmland (Gao et al. 2019). These ecological projects play a key role in enhancing 561 the ecological functions of regional water conservation and soil and water conservation 562 and accelerating the construction of a green ecological corridor in the YRD region. 563 However, ES degradation was still observed in some ecologically sensitive and rapidly 564 developed areas. The YRD region still faces a great challenge in achieving the "win565 win' goal of socioeconomic development and ecological protection. Reaching this goal 566 may be difficult because the trade-off/synergy relationships and their spatial 567 heterogeneity and impact factors have been neglected in ecological projects. Therefore, 568 it is important to integrate the complex interactions among ESs into the design and 569 implementation of various ecological projects to promote the efficiency of ecological 570 protection and restoration.

571 Second, our findings reveal the specific regions where trade-off/synergy relationships 572 exist, which is helpful information for decision making regarding trade-offs in specific 573 locations and implementing ES management more effectively. The YRD region can be 574 separated into three areas based on the intensity of land development, population 575 concentration and changes in ESs: optimized development area, key development area 576 and restricted development area. Different development strategies should be developed 577 for various areas. The optimized development area refers to the area where the carrying 578 capacity of resources and environment is saturated. This area is mainly distributed in 579 Shanghai, Hangzhou, and southern Jiangsu. We should take effective measures to 580 strictly control the scale and intensity of new construction land and appropriately 581 expand agricultural and ecological spaces. The key development area refers to the area 582 with great potential for the carrying capacity of resources and the environment. This 
area is mainly distributed in central Jiangsu, central Zhejiang, central Anhui and the coastal area. It is necessary to strengthen the capacity of industrial and population agglomeration, appropriately expand industrial and urban spaces, optimize the rural living space, and strictly protect the green ecological space. The restricted development area refers to the area with significant ecological sensitivity and a low carrying capacity of resources and the environment. This area is mainly distributed in northern Jiangsu, western Anhui and western Zhejiang. It is necessary to strictly control the scale of new construction land; promote the concentrated development of cities; strengthen the protection of water resources, ecological restoration and construction; and maintain the stability of the ecosystem structure and its functioning.

Third, the land development intensity in the YRD region was $17.1 \%$ in 2013, which was $15 \%$ higher than that due to Japan's Pacific coastal urban agglomeration, and the potential space available for subsequent construction is insufficient. Shanghai's development intensity is as high as $36 \%$, far more than that of Paris at $21 \%$ and that of London at $24 \%$. Due to extensive and unrestrained development, new development zones and industrial parks occupy too much land, which seriously affects the overall ecosystem structure and utilization efficiency of regional land space (Xu et al. 2020). Therefore, the "three red lines" (Ecological Protection Red Line, Cultivated land Protection Red Line, and Urban Development Boundary Red Line) policy for spatial planning was proposed to improve land-use efficiency (He et al. 2018). Despite the common acknowledgements of the importance of the three red lines in sustainable development, there are several issues that need to be addressed, including the lack of consideration of the trade-off relationships that exist among ESs, when identifying the three red lines. The establishment of the three red lines could lead to an ES trade-off, where one ES is promoted at the expense of other ESs.

\subsection{Limitations and further study}


609 Although this study obtained some interesting findings, some limitations exist. First,

610 trade-off/synergy research and ES management are based on the accurate measurement

611 of ESs. The reasonable assessment of ESs can provide basic and important data for

612 understanding the status of ESs in the YRD region. During the evaluation process,

613 however, subjective bias was introduced because some parameters of the ES models

614 were calculated by following relevant studies. The InVEST model ignores the regional

615 characteristics of geographical elements and assigns the same value to the same land

616 type, resulting in a deviation between the results of the evaluation and reality. Therefore,

617 future studies should improve and verify the parameters. Second, the TSD indicator

618 was developed and applied to analyze the trade-offs/synergies among ESs in the YRD

619 region and effectively quantify the complex relationships that exist between ESs.

620 However, a temporal scale was not included in this study. Some scholars have pointed

621 out that the relationship between ESs varies temporally (Wu et al. 2019; Braun et al.

622 2018). In addition, the reliability of the results regarding the trade-offs/synergies can be

623 improved by using long-term time series data. Therefore, future studies need to identify

624 the relationships between ESs using long-term series data to mitigate uncertainty about

625 the trade-offs/synergies that exist among ESs and analyze the impacts at the temporal

626 scale. Third, limitations exist in terms of the analysis of the influence mechanisms of

627 the trade-offs/synergies among ESs. This study investigated the effects of natural and

628 socioeconomic factors on the trade-off/synergy relationships among ESs by considering

629 six factors (ELE, PRE, TEM, GDP, POP, BUL). The findings suggest that these factors

630 have significant effects on ES relationships. However, the complex relationships

631 between ESs may be affected by other factors (e.g., soil properties, slope, solar radiation)

632 (Sun et al. 2020; Schirpke et al. 2019). It is of great importance to consider more

633 potential factors to improve the understanding of the influence mechanisms of the trade-

634 offs/synergies that exist among ESs.

635 5. Conclusions 
636 The results of the trade-off/synergy analysis enables decision makers to develop 637 effective regional planning and ecological management policies that promote 638 sustainable development. In this study, we investigated spatiotemporal changes in three 639 ESs, namely, CS, WP, and BC, in the YRD region from 2005 to 2015. The results 640 revealed that CS, WP, and HQ decreased by $1.17 \%, 2.49 \%$, and $3.38 \%$, respectively. 641 These variations in three key ESs in the YRD region imply that ESs have degraded 642 mainly due to intensive human disturbance in recent years. In addition to measuring the 643 trade-off/synergy relationships between multiple ESs, this study measure their 644 magnitude using an innovative indicator (TSD). The TSD indicator was proven to be 645 efficient for identifying the types of relationships that exist between ESs and 646 quantifying the intensity of the trade-offs/synergies. The relationships between the 647 factors and trade-offs/synergies were revealed by using MLR and GWR models. This 648 study demonstrated that the trade-off/synergy relationships presented significant 649 autocorrelations. The GWR model performed better than the MLR model in explaining 650 variations in the trade-off/synergy intensity, as the GWR model generated higher $\mathrm{R}^{2}$ 651 values and lower AIC values. The impacts of natural and socioeconomic factors on the 652 trade-offs/synergies were spatially heterogeneous rather than spatially consistent. Our 653 findings show that the GWR model can be used to obtain precise information on the 654 various roles of the related factors at different sites in the study area rather than 655 producing a global coefficient for the entire area. The trade-off/synergy intensity is 656 significantly correlated with meteorological, urbanization, and terrain factors. The 657 findings improve the understanding of the trade-off/synergy relationships that exist 658 among ESs and their influencing mechanisms. The trade-off/synergy relationships 659 among ESs in the YRD region are not only affected by environmental factors but also 660 significantly related to socioeconomic development. Furthermore, the spatial 661 heterogeneity of the trade-offs/synergies is well explained by the influencing factors. 662 The GWR model revealed that these relationships are spatially heterogeneous rather 
663

664

665

666

667

668

669

670

671

672

673

674

675

676

677

678

679

680

681

682

683

684

685

686

than spatially consistent relationships.

\section{Acknowledgements}

This work was supported by National Natural Science Foundation of China [grant number 41801197]; and China Postdoctoral Science Foundation [grant number 2019M652027].

\section{References}

Anselin L (1995) Local indicators of spatial association-LISA. Geographical Analysis 27: 93-115. doi: 10.1111/j.1538-4632.1995.tb00338.x

Asadolahi Z, Salmanmahiny A, Sakieh Y, Mirkarimi SH, Baral H et al (2018) Dynamic trade-off analysis of multiple ecosystem services under land use change scenarios: Towards putting ecosystem services into planning in Iran. Ecological Complexity 36: 250-260. doi: 10.1016/j.ecocom.2018.09.003

Bai Y, Chen Y, Alatalo JM, Yang Z, Jiang B (2020) Scale effects on the relationships between land characteristics and ecosystem services- a case study in Taihu Lake Basin, China. Science of the Total Environment 716: 137083. doi: 10.1016/j.scitotenv.2020.137083

Bai Y, Zheng H, Ouyang Z, Zhuang C, Jiang B (2013) Modeling hydrological ecosystem services and tradeoffs: A case study in Baiyangdian watershed, China. Environmental Earth Sciences 70(2): 709-718. doi: 10.1007/s12665-012-2154-5.

Baró F, Gómez-Baggethun E, Haase D (2017) Ecosystem service bundles along the urban-rural gradient: Insights for landscape planning and management. Ecosystem Services 24: 147-159. doi: 10.1016/j.ecoser.2017.02.021

Baró F, Palomo I, Zulian G, Vizcaino P, Haase D et al (2016). Mapping ecosystem 
687 service capacity, flow and demand for landscape and urban planning: a case study in 688 the Barcelona metropolitan region. Land Use Policy 57: 405-417. doi: 689 10.1016/j.landusepol.2016.06.006

690 Bennett EM, Peterson GD, Gordon LJ (2009) Understanding relationships among 691 multiple ecosystem services. Ecology Letters 12: 1394-1404. doi: 10.1111/j.1461$692 \quad 0248.2009 .01387 . x$

693 Bradford JB, D' Amato AW (2012) Recognizing trade-offs in multi-objective land 694 management. Frontiers in Ecology and the Environment 10(4): 210-216. doi: $695 \quad 10.1890 / 110031$

696 Braun D, Damm A, Hein L, Petchey OL, Schaepman ME (2018) Spatio-temporal trends 697 and trade-offs in ecosystem services: An Earth observation based assessment for 698 Switzerland between 2004 and 2014. Ecological Indicators 89: 828-839. doi: $699 \quad 10.1016 /$ j.ecolind.2017.10.016

700 Castro AJ, Verburg PH, Martín-López B, Garcia-Llorente M, Cabello J et al (2014)

701 Ecosystem service trade-offs from supply to social demand: a landscape-scale spatial 702 analysis. Landscape and Urban Planning 132: 102-110. doi: 703 10.1016/j.landurbplan.2014.08.009

704 Chisholm RA (2010) Trade-offs between ecosystem services: Water and carbon in a 705 biodiversity hotspot. Ecological Economics 69: 1973-1987. doi: $706 \quad$ 10.1016/j.ecolecon.2010.05.013

707 Chuai X, Huang X, Lai L, Wang W, Peng J et al (2013) Land use structure optimization 708 based on carbon storage in several regional terrestrial ecosystems across China. 709 Environmental Science \& Policy 25: 50-61. doi: 10.1016/j.envsci.2012.05.005

710 Cord AF, Bartkowski B, Beckmann M, Dittrich A, Hermans-Neumann K et al (2017) 711 Towards systematic analyses of ecosystem service trade-offs and synergies: main 
712 concepts, methods and the road ahead. Ecosystem Services 28: 264-272. doi:

713 10.1016/j.ecoser.2017.07.012

714 Dade MC., Mitchell MGE, McAlpine CA, Rhodes JR (2018) Assessing ecosystem 715 service trade-offs and synergies: the need for a more mechanistic approach. Ambio 48: 716 1116-1128. doi: 10.1007/s13280-018-1127-7

717 Darvill R, Lindo Z (2016) The inclusion of stakeholders and cultural ecosystem services 718 in land management trade-off decisions using an ecosystem services approach. 719 Landscape Ecology 31(3): 533-545. doi: 10.1007/s10980-015-0260-y

720 Feng, Q, Zhao W, Fu B, Ding J, Wang S (2017) Ecosystem service trade-offs and their 721 influencing factors: a case study in the Loess Plateau of China. Science of the Total 722 Environment 607-608: 1250-1263. doi: 10.1016/j.scitotenv.2017.07.079

723 Feng Q, Zhao W, Hu X, Liu Y, Daryanto S et al (2020) Trading-off ecosystem services 724 for better ecological restoration: A case study in the Loess Plateau of China. Journal of 725 Cleaner Production 257: 120469. doi: 10.1016/j.jclepro.2020.120469

726 Fotheringham AS, Brunsdon C (1999) Local forms of spatial analysis. Geographical 727 Analysis 31(4): 340-358. doi: 10.1111/j.1538-4632.1999.tb00989.x

728 Fotheringham AS, Charlton M, Brunsdon C (1997) Measuring Spatial Variations in 729 Relationships with Geographically Weighted Regression. In: Fischer MM, Getis A(eds) 730 Recent Developments in Spatial Analysis. Springer, Berlin, pp 60-82.

731 Gao J. Yu Z, Wang L, Vejre H (2019) Suitability of regional development based on 732 ecosystem service benefits and losses: A case study of the Yangtze River Delta urban 733 agglomeration, China. Ecological Indicators 107: 105579. doi: $734 \quad 10.1016 /$ j.ecolind.2019.105579

735 Goldstein JH, Caldarone G, Duarte TK, Ennaanay D, Hannahs N et al (2012) 736 Integrating ecosystem-service tradeoffs into land-use decisions. Proceedings of the 
737 National Academy of Sciences of the United States of America 109(19): 7565-7570.

738 doi: 10.1073/pnas.1201040109

739 Groot JCJ, Yalew SG, Rossing WAH (2018) Exploring ecosystem services trade-offs in

740 agricultural landscapes with a multi-objective programming approach. Landscape and

741 Urban Planning 172: 29-36. doi: 10.1016/j.landurbplan.2017.12.008

742 Haase D, Schwarz N, Strohbach M, Kroll F, Seppelt R. (2012) Synergies, trade-offs, 743 and losses of ecosystem services in urban regions: an integrated multiscale framework 744 applied to the Leipzig-Halle region, Germany. Ecology and Society 17(3): 22. doi: $745 \quad 10.5751 /$ ES-04853-170322

746 He J, Shi X, Fu Y, Yuan Y (2020) Evaluation and simulation of the impact of land use 747 change on ecosystem services trade-offs in ecological restoration areas, China. Land 748 Use Policy 99: 105020. doi: 10.1016/j.landusepol.2020.105020

749 He P, Gao J, Zhang W, Rao S, Zou C et al (2018) China integrating conservation areas 750 into red lines for stricter and unified management. Land Use Policy 71: 245-248. doi: $751 \quad$ 10.1016/j.landusepol.2017.11.057

752 Jopke C, Kreyling J, Maes J, Koellner T (2015) Interactions among ecosystem services 753 across Europe: Bagplots and cumulative correlation coefficients reveal synergies, trade754 offs, and regional patterns. Ecological Indicators 49: 46-52. doi: $755 \quad 10.1016 /$ j.ecolind.2014.09.037

756 Kubiszewski I, Costanza R, Anderson S, Sutton P (2017) The future value of ecosystem 757 services: Global scenarios and national implications. Ecosystem Services 26: 289-301. 758 doi: 10.1016/j.ecoser.2017.05.004

759 Landuyt D, Broekx S, Goethals PLM (2016) Bayesian belief networks to analyse trade760 offs among ecosystem services at the regional scale. Ecological Indicators 71: 327-335. 761 doi: 10.1016/j.ecolind.2016.07.015 
762 Langner A, Irauschek F, Perez S, Pardos M, Zlatanov T et al (2017) Value-based 763 ecosystem service trade-offs in multi-objective management in European mountain 764 forests. Ecosystem Services 26: 245-257. doi: 10.1016/j.ecoser.2017.03.001

765 Laterra P, Orue ME, Booman GC (2012) Spatial complexity and ecosystem services in 766 rural landscape. Agriculture, Ecosystem and Environment 154(S1): 56-67. doi: $767 \quad 10.1016 / j$.agee.2011.05.013

768 Lauf S, Haase D, Kleinschmit B (2014) Linkages between ecosystem services 769 provisioning, urban growth and shrinkage-A modeling approach assessing ecosystem 770 service trade-offs. Ecological Indicators 42: 73-94. doi: 10.1016/j.ecolind.2014.01.028

771 Locatelli B, Imbach P, Wunder S (2014) Synergies and trade-offs between ecosystem 772 services in Costa Rica. Environmental Conservation 41(1): 27-36. doi: $773 \quad 10.1017 / \mathrm{S} 0376892913000234$

774 MEA (Millennium Ecosystem Assessment) (2005) Ecosystems and human well-being. 775 Island Press, Washington D C.

776 Morán-Ordóñez A, Ameztegui A, De Cáceres M, de-Miguel S, Lefèvre F et al (2020)

777 Future trade-offs and synergies among ecosystem services in Mediterranean forests 778 under global change scenarios. Ecosystem Services 45: 101174. doi: $779 \quad 10.1016 /$ j.ecoser.2020.101174

780 Ndong GO, Villerd J, Cousin I, Therond O (2020) Using a multivariate regression tree 781 to analyze trade-offs between ecosystem services: Application to the main cropping 782 area in France. Science of The Total Environment. In Press. doi: 783 10.1016/j.scitotenv.2020.142815

784 Pan Y, Xu Z, Wu J (2013) Spatial differences of the supply of multiple ecosystem 785 services and the environmental and land use factors affecting them. Ecosystem Services 786 5: 4-10. doi: 10.1016/j.ecoser.2013.06.002 
787 Peng J, Hu X, Zhao M, Liu Y (2017) Research progress on ecosystem service trade788 offs: From cognition to decision-making. Acta Geographica Sinica 72(6): 960-973. doi: $789 \quad 10.11821 / \mathrm{dl} x \mathrm{xb} 201706002$

790 Schirpke U, Candiago S, Vigl LE, Jäger H, Labadini A et al (2019) Integrating supply, 791 flow and demand to enhance the understanding of interactions among multiple 792 ecosystem services. Science of The Total Environment 651: 928-941. doi: $793 \quad 10.1016 /$ j.scitotenv.2018.09.235

794 Sherrouse BC, Semmens DJ, Ancona ZH, Brunner NM (2017) Analyzing land-use 795 change scenarios for trade-offs among cultural ecosystem services in the Southern 796 Rocky Mountains. Ecosystem Services 26: 431-444. doi: 10.1016/j.ecoser.2017.02.003

797 Singer G. (2003) Productivity and global climate revisited: the sensitivity of tropical 798 forest growth to precipitation. Ecology 84(5): 1165-1170. doi: 10.1890/0012799 9658(2003)084[1165:PAGCRT]2.0.CO;2

800 Su S, Li D, Hu Y, Xiao R, Zhang Y (2014) Spatially non-stationary response of 801 ecosystem service value changes to urbanization in Shanghai, China. Ecological 802 Indicators 45: 332-339. doi: 10.1016/j.ecolind.2014.04.031

803 Sun X, Shan R, Liu F (2020) Spatio-temporal quantification of patterns, trade-offs and 804 synergies among multiple hydrological ecosystem services in different topographic 805 basins. Journal of Cleaner Production 268: 122338. doi: 10.1016/j.jclepro.2020.122338

806 Syrbe RU, Walz U (2012) Spatial indicators for the assessment of ecosystem services: 807 providing, benefiting and connecting areas and landscape metrics. Ecological 808 Indicators 21: 80-88. doi: 10.1016/j.ecolind.2012.02.013

809 Washbourne CL, Goddar, MA, Provost GL, Manning DAC, Manning P (2020) Trade810 offs and synergies in the ecosystem service demand of urban brownfield stakeholders. 811 Ecosystem Services 42: 101074. doi: 10.1016/j.ecoser.2020.101074 
812 Wu Y, Tao Y, Yang G, Ou W, Pueppke S et al (2019) Impact of land use change on

813 multiple ecosystem services in rapidly urbanization Kunshan City of China: Past 814 trajectories and future projections. Land Use Policy 85: 419-427. doi: 815 10.1016/j.landusepol.2019.04.022

816 Xu F, Wang Z, Chi G, Zhang Z (2020) The impacts of population and agglomeration 817 development on land use intensity: New evidence behind urbanization in China. Land 818 Use Policy 95: 104639. doi: 10.1016/j.landusepol.2020.104639

819 Xu X, Yang G, Tan Y, Liu J, Hu H (2018) Ecosystem services trade-offs and 820 determinants in China's Yangtze River Economic Belt from 2000 to 2015. Science of 821 the Total Environment 634: 1601-1614. doi: 10.1016/j.scitotenv.2018.04.046

822 Yu H, Gong H, Chen B, Liu K, Gao M (2020) Analysis of the influence of groundwater 823 on land subsidence in Beijing based on the geographical weighted regression (GWR) 824 model. Science of The Total Environment 738: 139405. doi: $825 \quad$ 10.1016/j.scitotenv.2020.139405

826 Zhang Y, Liu Y, Zhang Y, Liu Y, Zhang G et al (2018) On the spatial relationship 827 between ecosystem services and urbanization: a case study in Wuhan, China. Science 828 of The Total Environment 637-638: 780-790. doi: 10.1016/j.scitotenv.2018.04.396

829 Zhang Z, Liu Y, Wang Y, Liu Y, Zhang Y et al (2020) What factors affect the synergy 830 and tradeoff between ecosystem services, and how, from a geospatial perspective? 831 Journal of Cleaner Production 257: 120454. doi: 10.1016/j.jclepro.2020.120454

832 Zheng H, Li Y, Robinson BE, Liu G, Ma D et al (2016) Using ecosystem service trade833 offs to inform water conservation policies and management practices. Frontiers in 834 Ecology and the Environment 14(10): 527-532. doi: 10.1002/fee.1432

835 Zhong L, Wang J, Zhang X, Ying L (2020) Effects of agricultural land consolidation on 836 ecosystem services: Trade-offs and synergies. Journal of Cleaner Production 264: 
837 121412. doi: $10.1016 /$ j.jclepro.2020.121412

838 Zhou D, Tian Y, Jiang G (2018) Spatio-temporal investigation of the interactive

839 relationship between urbanization and ecosystem services: Case study of the Jingjinji 840 urban agglomeration, China. Ecologial Indicators 95: 152-164. doi:

$841 \quad 10.1016 /$ j.ecolind.2018.07.007

842 Zhou ZX, Li J, Guo ZZ, Li T (2017) Trade-offs between carbon, water, soil and food in 843 Guanzhong-Tianshui economic region from remotely sensed data. International Journal 844 of Applied Earth Observation and Geoinformation 58: 145-156. doi: $845 \quad$ 10.1016/j.jag.2017.01.003

846 

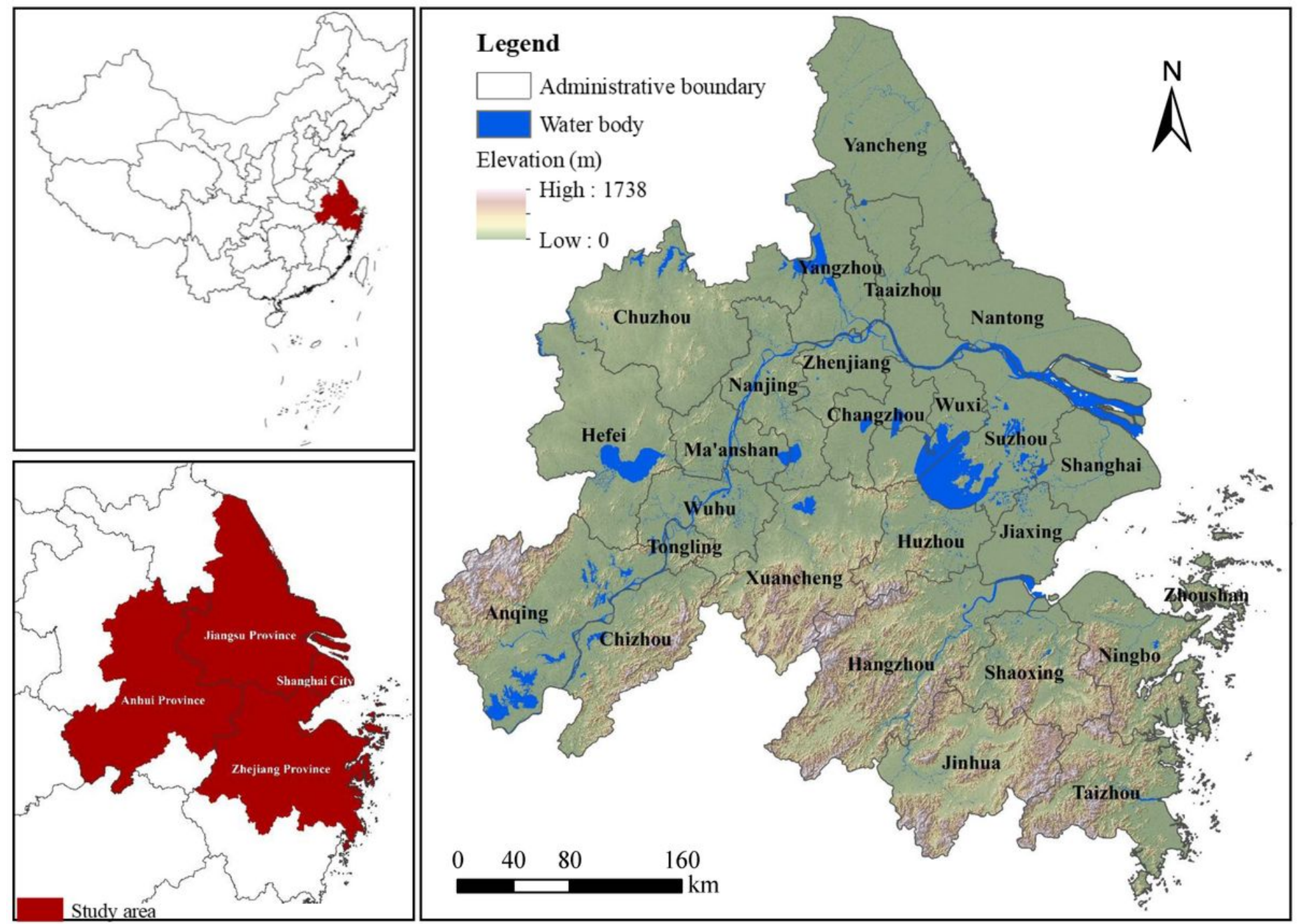

\section{Figure 1}

The YRD Note: The designations employed and the presentation of the material on this map do not imply the expression of any opinion whatsoever on the part of Research Square concerning the legal status of any country, territory, city or area or of its authorities, or concerning the delimitation of its frontiers or boundaries. This map has been provided by the authors. 


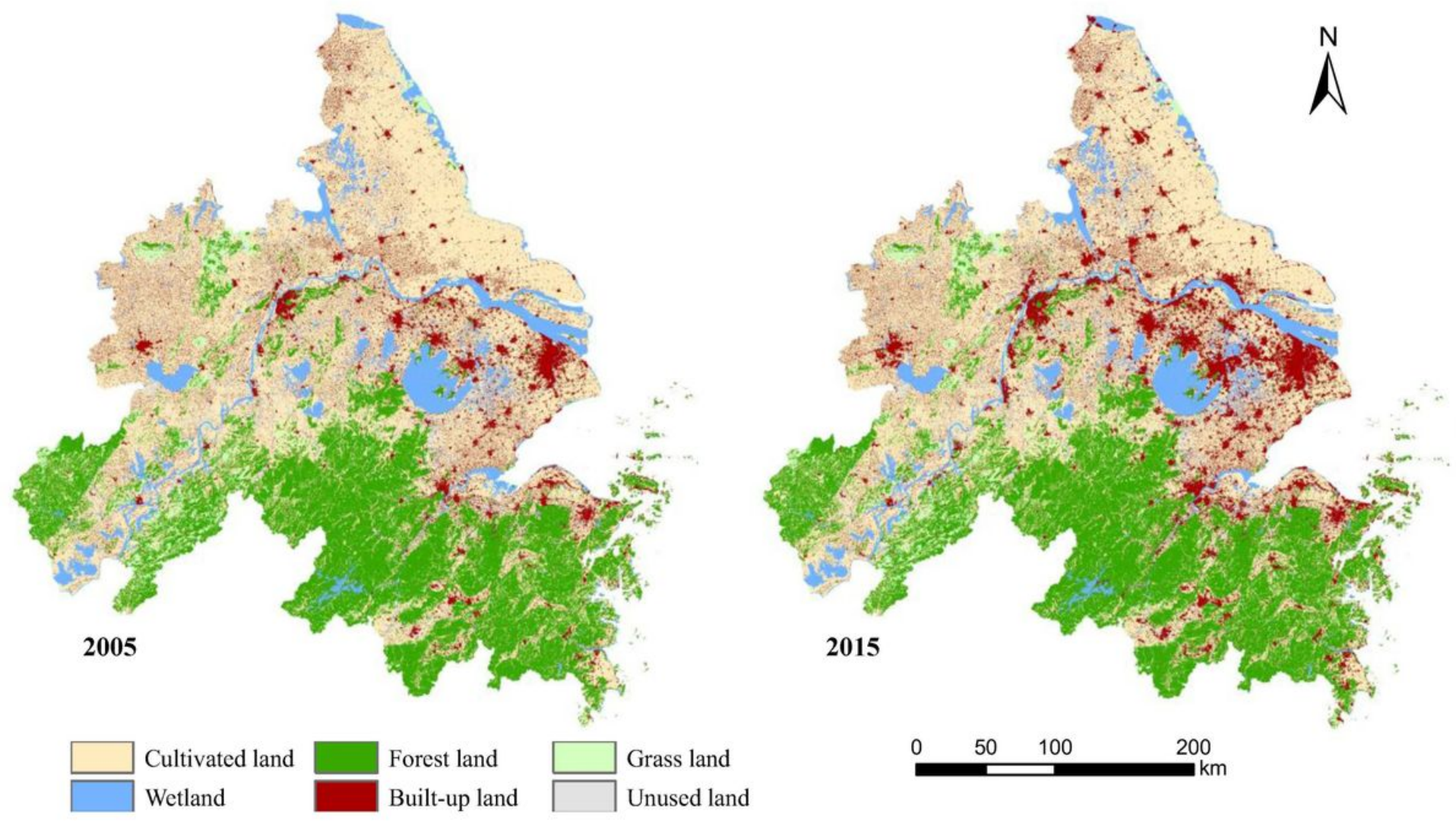

Figure 2

Land cover map of the YRD region in 2005 and 2015. Note: The designations employed and the presentation of the material on this map do not imply the expression of any opinion whatsoever on the part of Research Square concerning the legal status of any country, territory, city or area or of its authorities, or concerning the delimitation of its frontiers or boundaries. This map has been provided by the authors. 


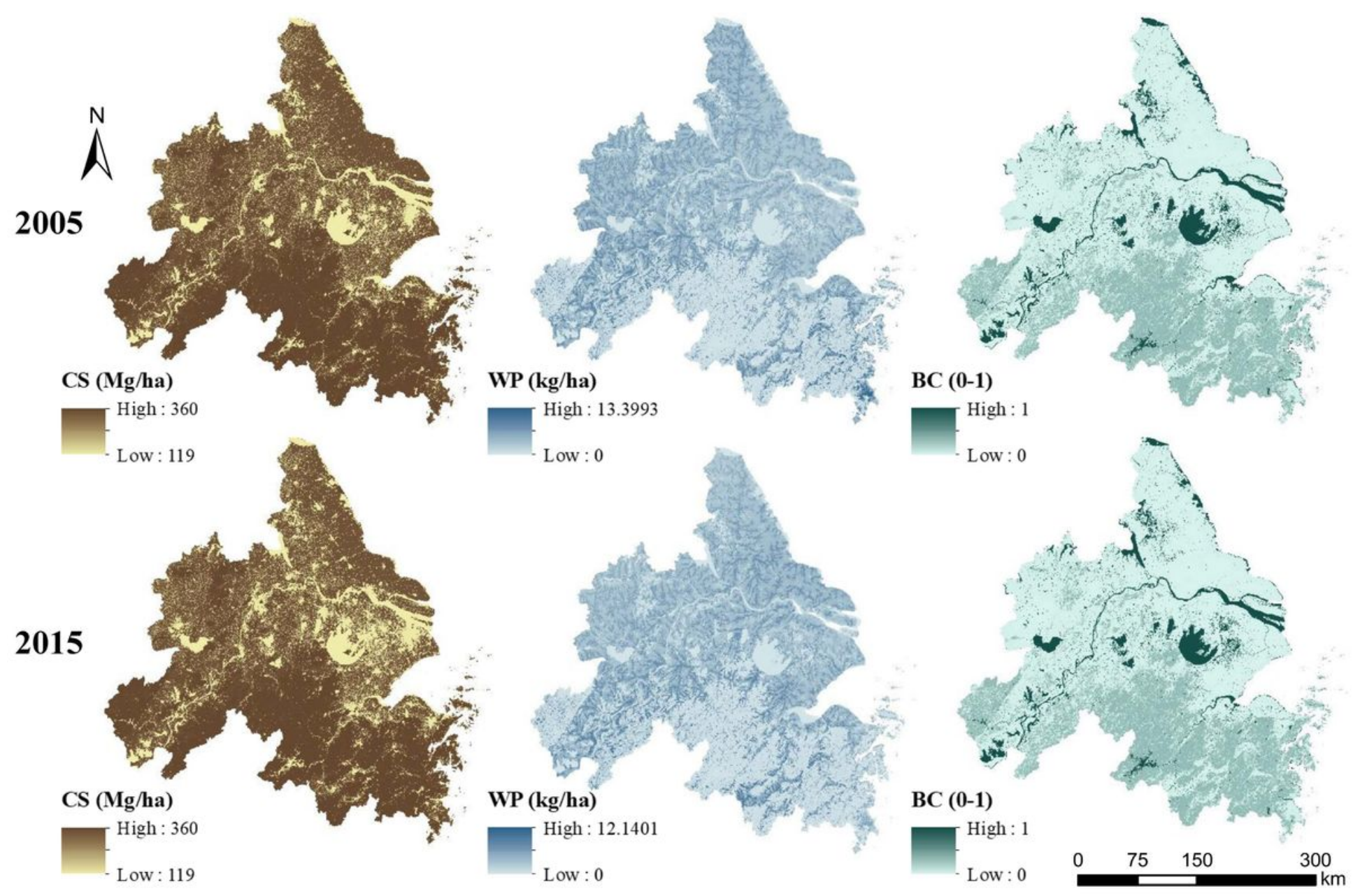

\section{Figure 3}

Spatial patterns of ESs in the YRD region at the grid scale (CS: carbon storage; CP: crop production; WP: water purification; BC: biodiversity conservation). Note: The designations employed and the presentation of the material on this map do not imply the expression of any opinion whatsoever on the part of Research Square concerning the legal status of any country, territory, city or area or of its authorities, or concerning the delimitation of its frontiers or boundaries. This map has been provided by the authors.

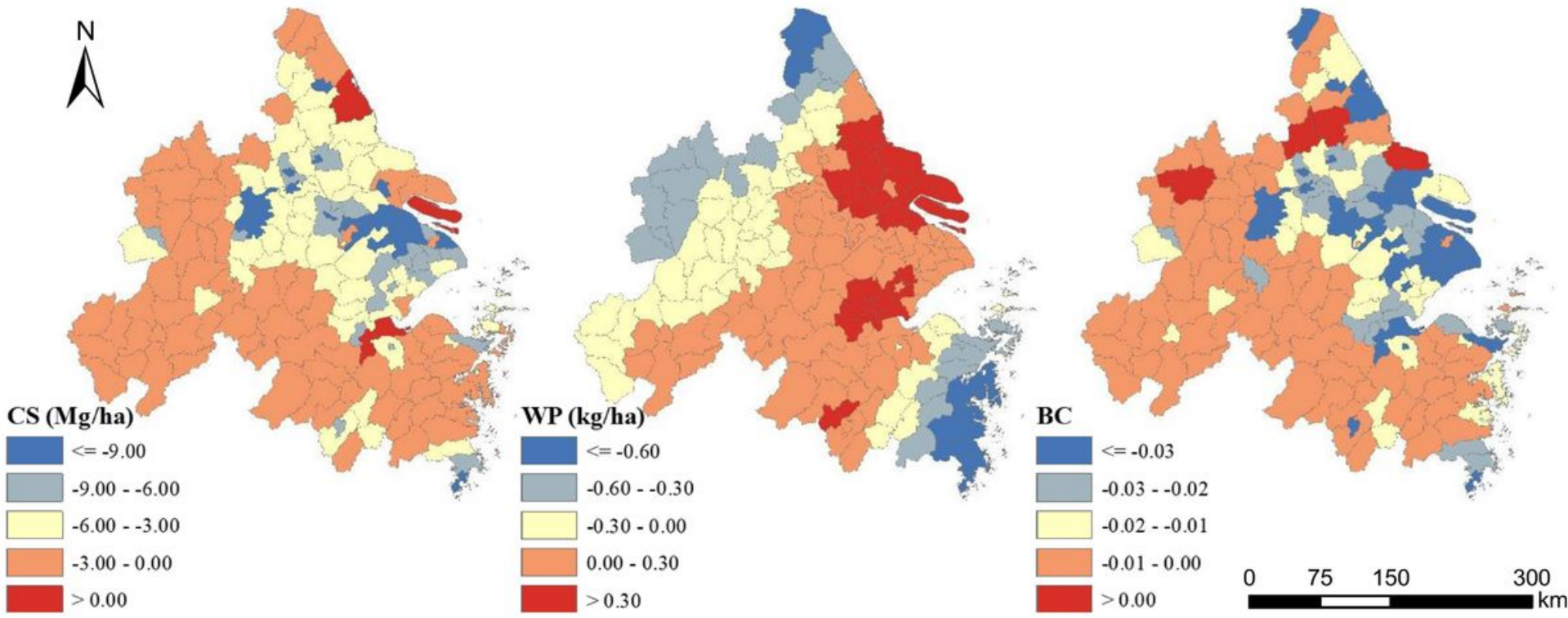




\section{Figure 4}

Spatial patterns of ES variations at the county scale in the YRD region (CS: carbon storage; CP: crop production; WP: water purification; BC: biodiversity conservation). Note: The designations employed and the presentation of the material on this map do not imply the expression of any opinion whatsoever on the part of Research Square concerning the legal status of any country, territory, city or area or of its authorities, or concerning the delimitation of its frontiers or boundaries. This map has been provided by the authors.
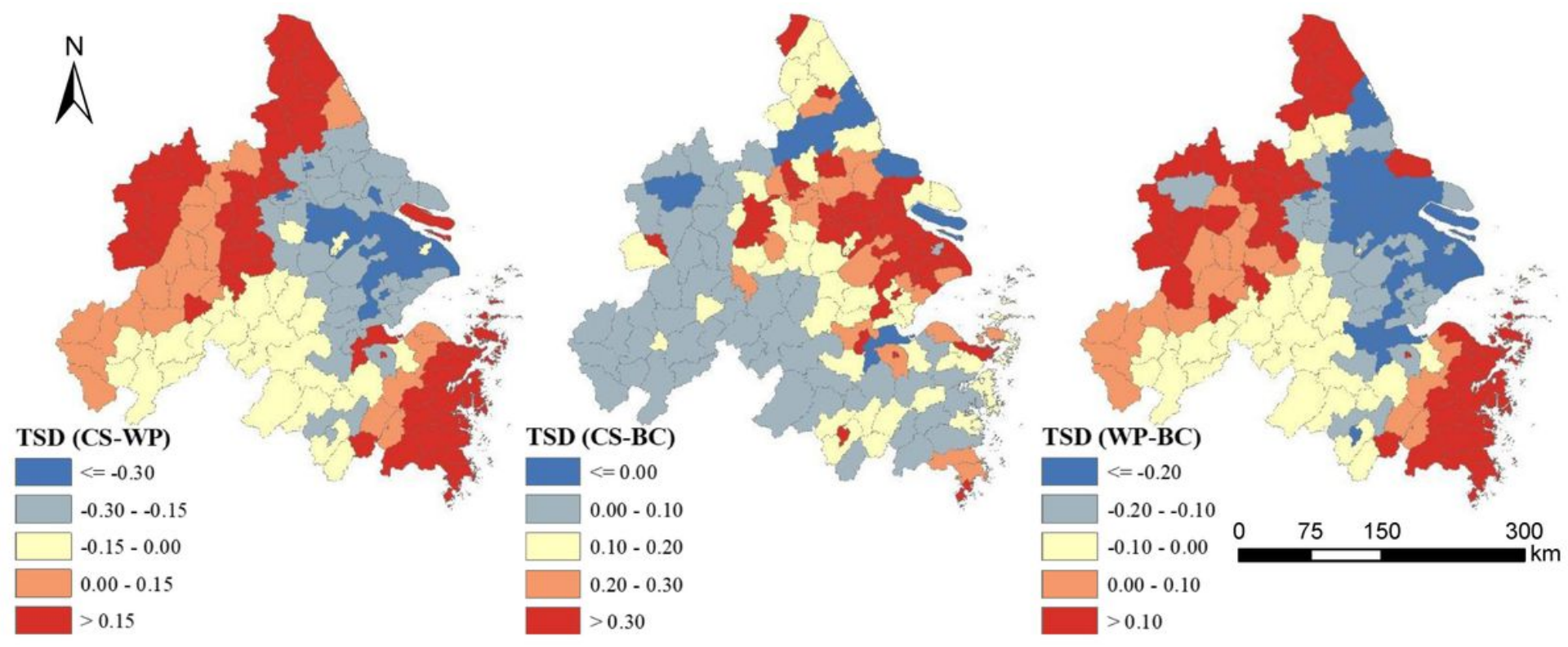

Figure 5

Spatial patterns of the synergies and trade-offs (measured by TSD) among multiple ESs at the county scale in the YRD region (CS: carbon storage; CP: crop production; WP: water purification; BC: biodiversity conservation). Note: The designations employed and the presentation of the material on this map do not imply the expression of any opinion whatsoever on the part of Research Square concerning the legal status of any country, territory, city or area or of its authorities, or concerning the delimitation of its frontiers or boundaries. This map has been provided by the authors. 


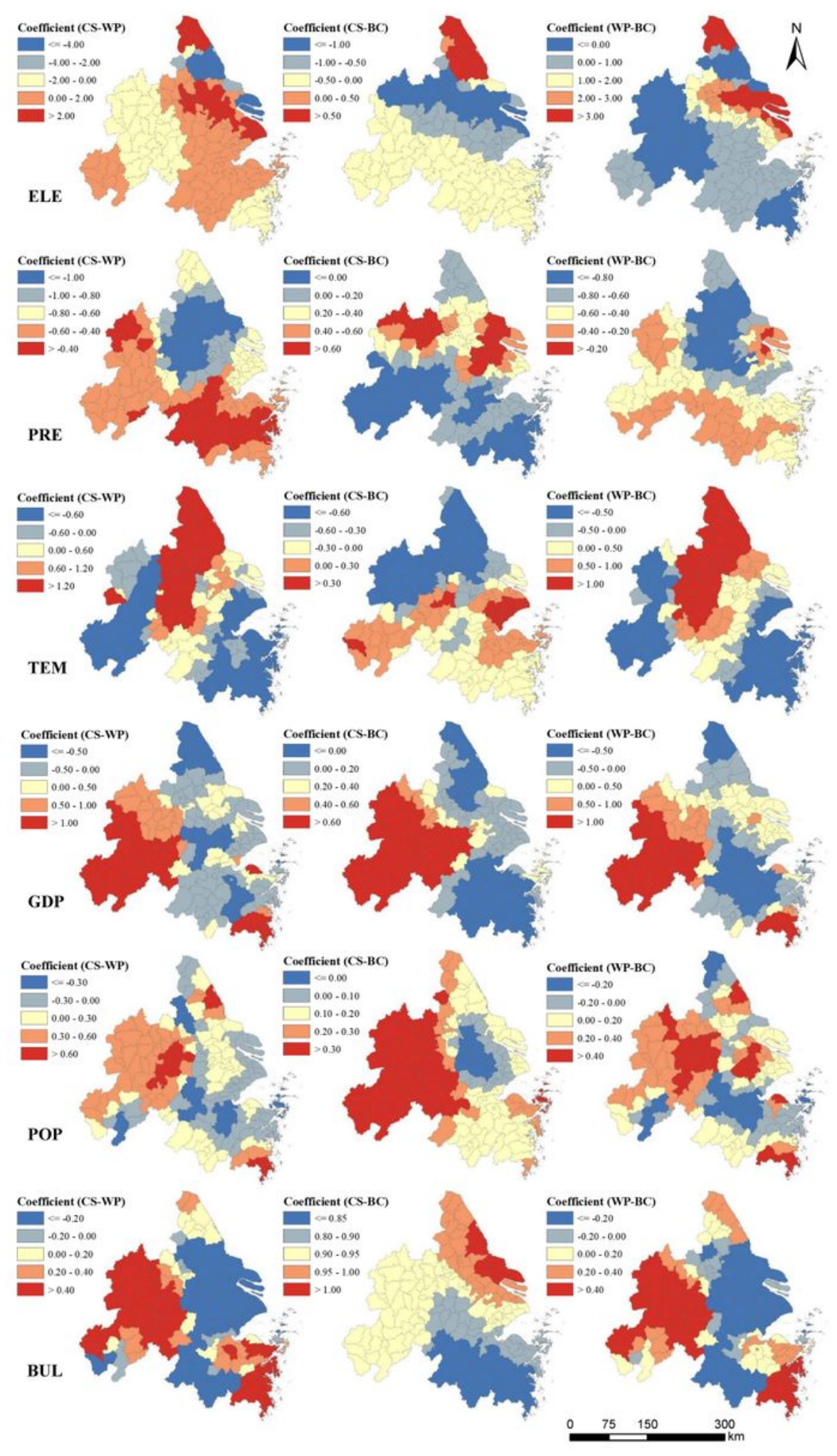

\section{Figure 6}

Coefficients of the relationship between the TSD of paired ESs and six variables using the GWR model. Note: The designations employed and the presentation of the material on this map do not imply the expression of any opinion whatsoever on the part of Research Square concerning the legal status of any country, territory, city or area or of its authorities, or concerning the delimitation of its frontiers or boundaries. This map has been provided by the authors. 


\section{Supplementary Files}

This is a list of supplementary files associated with this preprint. Click to download.

- Supplement.docx 